\title{
Greenland ice-sheet surface properties observed by the Seasat-A scatterometer at enhanced resolution
}

\author{
DAVID G. LONG \\ Electrical and Computer Engineering Department, Brigham Young University, Provo, Utah 84602, U.S.A. \\ MARK R. DRINKWATER \\ Jet Propulsion Laboratory, California Institute of Technology, Pasadena, California 91109, U.S.A.
}

\begin{abstract}
For 3 months in 1978, the $14.6 \mathrm{GHz}$ Seasat-A scatterometer (SASS) measured the normalized microwave-radar back-scatter coefficient of the Earth's surface for the purpose of estimating near-surface vector winds over the ocean. SASS also made back-scatter measurements over land and ice regions; however, the application of this data has been limited due to the low $(50 \mathrm{~km})$ resolution of the measurements. Using a new technique for generating $6 \mathrm{~km}$ enhanced-resolution SASS images of the radar back-scatter characteristics, we present a study of the 1978 condition of the Greenland ice sheet. We derive a timeseries of back-scatter images spanning the period July-September 1978. These images show the extent of summer ablation along the ice-sheet periphery. Using the data and models relating firn structure and condition to radar back-scatter characteristics, we delineate and map the seasonal extent of zones which appear to correspond to dry-snow, percolation, wet-snow, and ablation facies, over virtually the entire ice sheet. The results provide a base line with which to compare current (ERS-1) and future Greenland radar maps of snow- and ice-surface conditions.
\end{abstract}

\section{INTRODUCTION}

Increasing interest in the influence of major ice sheets upon global climate has resulted in a scientific mandate to record and monitor the extent and surface conditions of the Earth's major ice bodies. Satellite-imaging technology first presented glaciologists with a synoptic-scale mapping tool in the early 1970s. But the glacier and ice-sheet inventory which began with such visible wavelength systems is limited in its temporal resolution and seasonality and is restricted to cloud-free daylight hours. The appearance of spaceborne microwave radar, with Seasat in 1978, provided a new tool with which to study glacierized regions. Microwave radar mitigates the need for optimal meteorological conditions and solar illumination and can provide glaciologists with a high-resolution database in either image or non-image form. It is therefore suited to the task of frequent mapping of the polar regions.

The Seasat-A scatterometer (SASS) made nominally $50 \mathrm{~km}$ resolution measurements of the Ku-band $(14.6 \mathrm{GHz})$ normalized microwave-radar back-scatter coefficient $\left(\sigma^{\circ}\right)$ at a variety of incidence angles over two $500 \mathrm{~km}$ wide swaths separated by a $400 \mathrm{~km}$ nadir gap. From ocean measurements of $\sigma^{\circ}$, the near-surface wind velocity can be inferred using a geophysical model function relating $\sigma^{\circ}$ and the vector wind (Jones and others, 1982). While $50 \mathrm{~km}$ resolution is adequate for ocean studies, it limits application of the data in ice studies. Despite this drawback, SASS data were used by Thomas and others (1985) to illustrate the application of ice-sheet-wide coverage by an active microwave sensor for mapping regional melting. They point out that these valuable SASS data warrant further work to understand the nature of microwave interactions with glacier ice.

Recent controversy over changes in Greenland icesheet elevation began with postulated growth as observed from a decade of satellite-altimetric measurements (Zwally and others, 1989). The explanation for ice-sheet growth was that it was consistent with the generally warmer temperatures in the Northern Hemisphere this century and induced by greater precipitation. Recent results by Chapman and Walsh (1993) further fuel this controversy, with air temperatures showing that localized cooling of up to $-0.6 \mathrm{deg}$ per decade has consistently taken place over central and southern Greenland in the last three decades. Furthermore, the trend is observed in all seasons throughout the year. Whether growth results from reduced ablation as suggested by Braithwaite and others (1992) or increased precipitation is a thorny issue. These inconsistencies make it imperative to build up a spatial picture of areas of ice-sheet ablation and accumulation in addition to base line surveying by altimeters. Satellite radar offers the possibility of generating maps or images of back-scatter to reflect distinctive ice-sheet snow-and-ice physical zones or facies. Facies recorded by Benson (1962) were recently modified by Williams and others (1991) to update our understanding of the linkages between 
generalized physical models of these facies and what may be imaged by various types of satellite sensors. Further advances coupling field programs with airborne remotesensing campaigns and satellite imaging (ERS-1 and JERS-1) are reported by Jezek and Gogineni (1992). The latter show evidence to support links between physical models of glacier facies and unique combinations of scattering mechanisms, which may ultimately be recognized and used as a basis for delineating climate-related snow-and-ice regimes on the Greenland ice sheet.

In this paper we apply a new method for generating enhanced-resolution $\sigma^{\circ}$ images from Greenland SASS data. The technique generates up to $4-5 \mathrm{~km}$ resolution images from the original $50 \mathrm{~km}$ data (Long and others, 1993). While these enhanced-resolution images can only be considered "high"-resolution when compared to the intrinsic resolution of SASS, they are useful for a largescale study of the Greenland ice sheet's surface properties. Our results are an initial step toward the goal of achieving a facies mapping capability. They provide a 1978 historical base line for future studies.

The paper is organized as follows. First, we examine vertically polarized (VV-pol) $\sigma^{\circ}$ over several small study regions shown in Figure 1, briefly describing the imaging technique and its limitations. Secondly, we present a time-series of $6 \mathrm{~km}$ enhanced-resolution Ku-band images in which seasonal change between July and September 1978 is dramatically evident. Thirdly, with support from simplified scattering models and ancillary information, the extent of the accumulation and ablation facies is

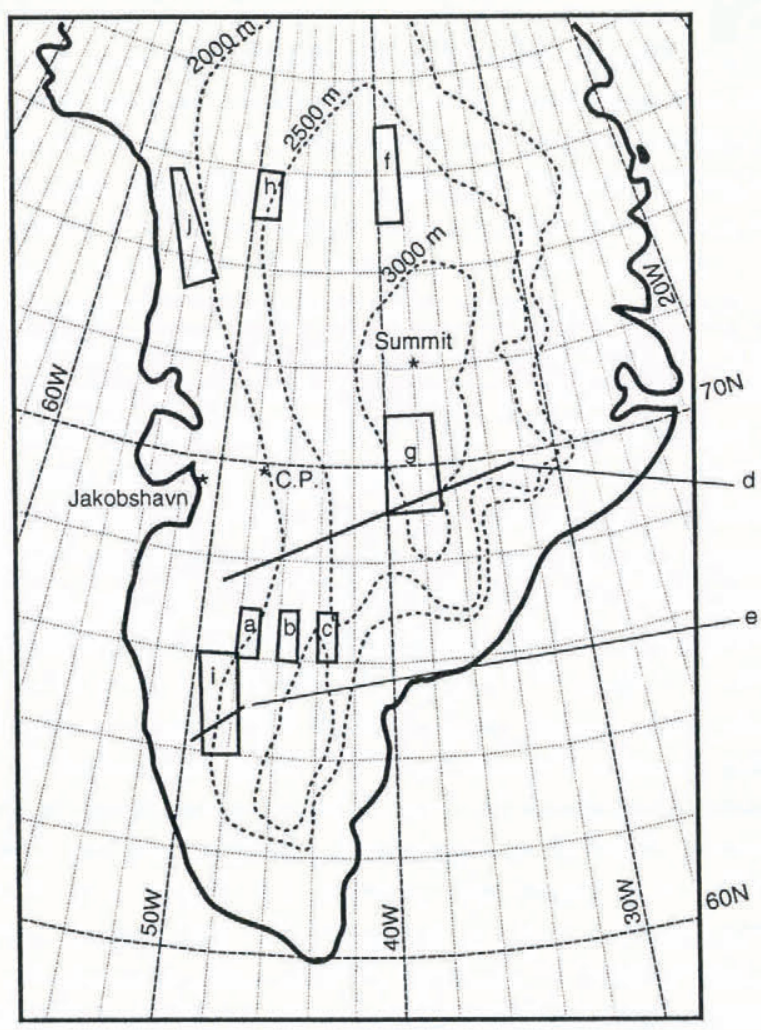

Fig. 1. Greenland base map showing the location of sample areas discussed in the text. Lettered boxes are sample location regions for SASS data, while transects $d$ and $e$ are locations of comparisons with aircraft over-flight microwave data. noted and the surface-melt zone mapped as a function of time. Finally, based on these data, key facies boundaries are mapped over almost the entire ice sheet.

\section{SPATIAL AND TEMPORAL VARIATIONS IN ICE-SHEET PHYSICAL PROPERTIES}

The surface of the Greenland ice cap may be subdivided or classified into a variety of types within which nearsurface geophysical properties have unique characteristics. These zones or facies were first measured and described in detail by Benson (1962, 1967). Williams and others (1991) investigated the appearance of snow and ice facies in optical satellite remote-sensing data but concluded that boundaries between some facies are not always distinguishable by strong gradients in surface properties. The wet- and dry-snow lines, for instance, may only be discerned by measurements which penetrate several meters into the surface of the snow and ice. Since visible wavelengths are unable to "see" sub-surface variations in properties, in this paper we utilize the penetrating capability of microwaves demonstrated by Rott and others (1985), Swift and others (1985) and more recently by Bindschadler and others (1987) and Jezek and others $(1990,1993)$, who have demonstrated that L- and C-band microwave radar is particularly sensitive to variations in both surface and sub-surface characteristics of the Greenland ice sheet.

\section{The summer-fall progression of surface change}

Snow metamorphism and the resulting stratigraphy of the snow and firn are principally influenced by the thermal regime during seasonal change, or the presence of meltwater. General progressions in upper ice-sheet surface properties closely follow the thermal forcing in the upper few meters of the snowpack. The warmer summer months and particularly the summer-fall transition cause rapid changes in Greenland ice-sheet surface properties. The altitude, latitude, and topography, however, modify environmental conditions such that rates of seasonal change vary spatially.

Diagenetic changes in the structure of snow and firn can take place without melt, but are accelerated with higher temperatures, until a point at which melting may take place. When summer temperatures in the upper snowpack increase above $-10^{\circ} \mathrm{C}$ there is a significant increase in the vapor pressure of ice. In firn strata this can lead to vapor transport and sublimation. The net result is the destruction of original precipitated snow-crystal forms, increased grain-sizes and increased bonding between grains. These changes in snow and firn are common to the spring and summer months in the drysnow zone at elevations too high to suffer actual melting.

Further downslope, as summer surface-air temperatures increase, diagenesis takes place much more rapidly and dramatically by melting. Echelmeyer and others (1992) describe the seasonal variation in surface temperatures at around $1500 \mathrm{~m}$ altitude and at varying depths beneath the surface. After a period of freeze-thaw fluctuations in late June, which grows grains in the lowerelevation areas to the order of $1 \mathrm{~mm}$ in diameter, surface 
temperature stabilizes at $0^{\circ} \mathrm{C}$ around $1 \mathrm{July}$ (Julian day 183). After this date the melt front moves upslope of this altitude, as far as the dry-snow line at the height of the summer melt. Below the dry-snow line, meltwater often percolates downwards preferentially in pipes or channels. Often it encounters obstructions or simply snow below the freezing point, whereupon it filters laterally to form layers or buried ice lenses and glands (Pfeffer and others, 1990) parallel to the strata. The pipes, which feed these hard ice layers with meltwater, may themselves freeze. These glands are vertically extended ice masses, and are found in association with ice lenses or layers, typically in the percolation zone.

At lower altitudes, where melting is significant, the upper snowpack typically becomes isothermal. Definitions used for wetting are applied strictly in the sense of Benson (1967) and are as follows. "Wet snow" is at $0^{\circ} \mathrm{C}$ and often wet throughout the upper meter of snow. When wet snow becomes saturated down to the previous summer surface it is known as "soaked snow". Temperature cycling and fall cooling result in wet snow refreezing as "iced firn". Such dense layers provide stratigraphic markers indicating surface melting.

\section{Physical influences on microwave signatures}

The principal parameter affecting the microwave response of the ice-sheet surface is the presence of liquid water. It changes the dielectric properties of snow and ice so significantly that it regulates the reflection or transmissivity at the surface and limits the contribution of sub-surface or volume-scattering effects by absorption and extinction within the upper layers (Rott and others, 1985). Seasonal modulations of $\sigma^{\circ}$ in SASS data are a demonstration of the sensitivity to the transitions in surface and sub-surface properties.

Important to the microwave scattering mechanism is the layering which develops as a consequence of the snowaccumulation patterns and the changes affected by seasons. Such stratigraphy is preserved over time, and can often be correlated over scales of tens of kilometers. A stratigraphic discontinuity forms as a consequence of seasonal changes. One such distinct boundary takes the form of a coarse-grained, low-density layer, overlain by a finer-grained, harder layer of higher density. This occurs slightly above the uppermost evidence of the previous summer's surface melting. Benson (1967) observed the formation of this sequence under strong negative temperature gradients in mid- to late August, during the short fall season. It was normally fully formed by 10 September and could be traced over long transects, but became difficult to trace beneath the altitude at which significant melting takes place (due to obliteration by meltwater processes). In the percolation zone, the important stratigraphic horizons are seasonal markers such as iced firn or ice lenses. By this stage in the melt season, the uppermost of these boundaries are related to significant spring or summer climatic events while a relatively distinct surface may remain beneath the previous year's annual accumulation (i.e. summer surface).

Since snow-surface wetness decreases incrementally with surface temperature and altitude there is not expected to be a large step in the observed back-scatter between the wet- and dry-snow regimes in the summer months. Rather, during fall cooling, with cooler and drier conditions (as the active surface layer refreezes and snowfall takes place), the increasing penetration of microwaves will sense the fundamental differences between the dry-snow regime and the percolation facies further downslope. Due to rapid grain growth and the formation of ice layers and lenses beneath the surface in the percolation zone, the higher resulting back-scatter should more sharply delimit the extent of surface melt (i.e. the dry-snow line) during autumn. Thus, at the end of the fall, we should begin to see the development of a sharp gradient in the back-scatter map.

Differences in physical properties between the percolation zone and wet-snow or saturated-snow zones after fall freeze-up has taken place should be sufficient for considerable variations in snow back-scattering. Also, the hard ice surface remaining below the equilibrium line, (i.e. in the ablation zone), should have a different appearance from the snow-covered areas. In the case of the wet snow or ice near the ice margins, surface penetration of microwaves is negligible and the shape of the surface roughness autocorrelation function is most important for determining the value of $\sigma^{\circ}$ obtained by SASS. The surface roughness standard-deviation and correlation-length scale used to describe this function will drive the surface scattering and the form of the backscatter relationships.

\section{SPATIAL AND TEMPORAL VARIATION IN BACK-SCATTER}

The SASS made $14.6 \mathrm{GHz}$ measurements of $\mathrm{HH}$ - and VV-polarized $\sigma^{\circ}$ on ascending and descending orbits at various azimuth and incidence angles. The nominal resolution was approximately $50 \mathrm{~km}$ over an irregular grid with hexagonal resolution cells (Long and others, 1993). Over Greenland, a given area was generally observed twice each day.

For glacial ice, $\sigma^{\circ}$ is a function of the measurement incidence angle $\theta$ (Swift and others, 1985). In the range $\theta \in\left[23^{\circ}, 55^{\circ}\right], \sigma^{\circ}$ (in $\mathrm{dB}$ ) is approximately a linear function of $\theta$, i.e.

$$
\sigma^{\circ}(\theta)=A+B\left(\theta-40^{\circ}\right)
$$

where the coefficients $A$ and $B$ depend on surface characteristics, polarization and azimuth angle. $A$ is the $40^{\circ}$ "incidence angle-normalized $\sigma^{\circ}$ ", while $B$ describes the dependence of $\sigma^{\circ}$ on $\theta$. Due to the wide range in $\theta$, we will use $A$ and $B$ rather than $\sigma^{\circ}$. In Equation (1), $40^{\circ}$ represents the mean $\theta$ of the observations. Over Greenland, $\sigma^{\circ}$ may also be affected by the azimuth angle of the observation. Swift and others (1985) observed approximately $1 \mathrm{~dB}$ azimuthal modulation (about the mean) when examining $\sigma^{\circ}$ over a $360^{\circ}$ azimuth range. For a given area, SASS measurements show negligible azimuthal modulation of $\sigma^{\circ}$. However, this may be due to the limited range of azimuth angles $\left(<100^{\circ}\right)$. In subsequent processing, $\sigma^{\circ}$ was assumed to have no azimuth angle modulation. Ignoring such modulation is recognized as a limitation or drawback in this current work. Nonetheless, 
airborne-SAR data, collected over Greenland by the Jet Propulsion Laboratory in 1991 at longer wavelengths, indicate that azimuthal modulations are only observed in the percolation zone, where the mechanism is suggested to be preferentially aligned dipole scatterers (J. van Zyl, personal communication). This appears consistent with scattering from ice glands, vertical pipes and lenses, as suggested by Swift and others (1985). These results from SASS data acquired at VV and $\mathrm{HH}$ polarizations confirm the lack of polarization dependence at $\mathrm{Ku}$-band which was observed by Swift and others (1985). Since recent Cband and L-band radar data analyzed by Jezek and others (1993) also show this same tendency, it was felt unnecessary in the context of this paper to show comparisons between both VV- and HH-pol SASS data and other data sources. For the purpose of data presentation we limit graphical presentation of SASS results to VV polarization only, and subsequent comparisons with airborne-radar data should be regarded independently of polarization.

To illustrate spatial and temporal variations in $A$ and $B$, we plot VV-pol data versus Julian day (1978) from three $1^{\circ} \times 1^{\circ}$ regions (regions a-c in Figure 1) along a traverse at $66^{\circ} \mathrm{N}$ latitude. Figures 2, 3 and 4 show the corresponding SASS data for these regions in ascending order of altitude. In the upper panel of Figures 2a, 3a and 4a, $A$ and $B$ coefficients are plotted as solid and dashed lines, respectively. To generate these curves, $A$ and $B$ were first estimated over a $10 \mathrm{~d}$ window using linear regression of the $\sigma^{\circ}$ versus incidence angle. The window was moved $1 \mathrm{~d}$ and the process repeated to estimate timeaveraged coefficients. To illustrate changes in the measurements as a function of time, the estimated $B$ value in the upper panel was used to estimate an $A$ value for each measurement. The resulting $A$ estimates are plotted in the lower panel of Figures 2a, 3a and $4 \mathrm{a}$ as scattered points. A $10 \mathrm{~d}$ moving average of these $A$ values is included as a solid line in the lower panel. The scatter in $A$ as well as the occurrence of significant, rapid variations are evident. Gaps are due to missing data.

Significant changes occur in $A$ as a function of time, with a moderation in these changes with ice-sheet altitude. Initially low $A$ values (in July and early August) are attributed to summer melt and the creation
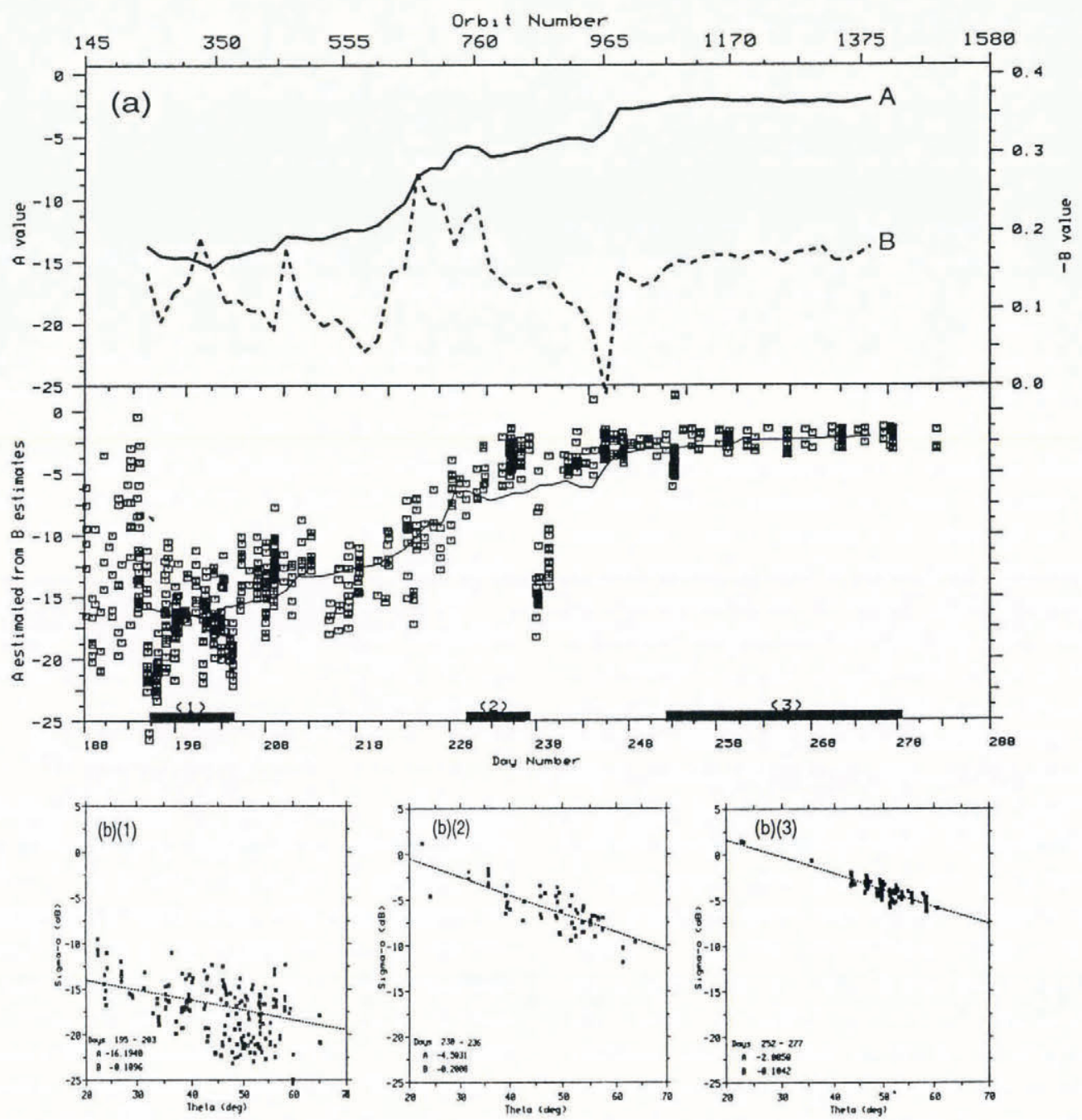

Fig. 2. (a) Plots of $A$ and $B$ for region $a$. $A$ and $B$ coefficients derived using a linear regression of $V V$-pol $\sigma^{\circ}$ versus $\theta$ were computed for a $10 \mathrm{~d}$ window centered at each time-indexed point in the upper panel. The window was shifted 1 day and $A$ and $B$ recomputed. The $B$ coefficient is shown as a dashed line in the upper panel. Using the $B$ estimate, the individual $\sigma^{\circ}$ measurements were incidence-angle "corrected" and plotted in the lower panel. (b) VV-pol $\sigma^{\circ}$ versus $\theta$ in region a for Julian days: (1) 195-203, (2) 230-236 and (3) 252-277. The dotted line shows the linear regression of $\sigma^{\circ}$ versus $\theta$ with the fit coefficients ( $A$ and $B$ ) given for each subfigure. 

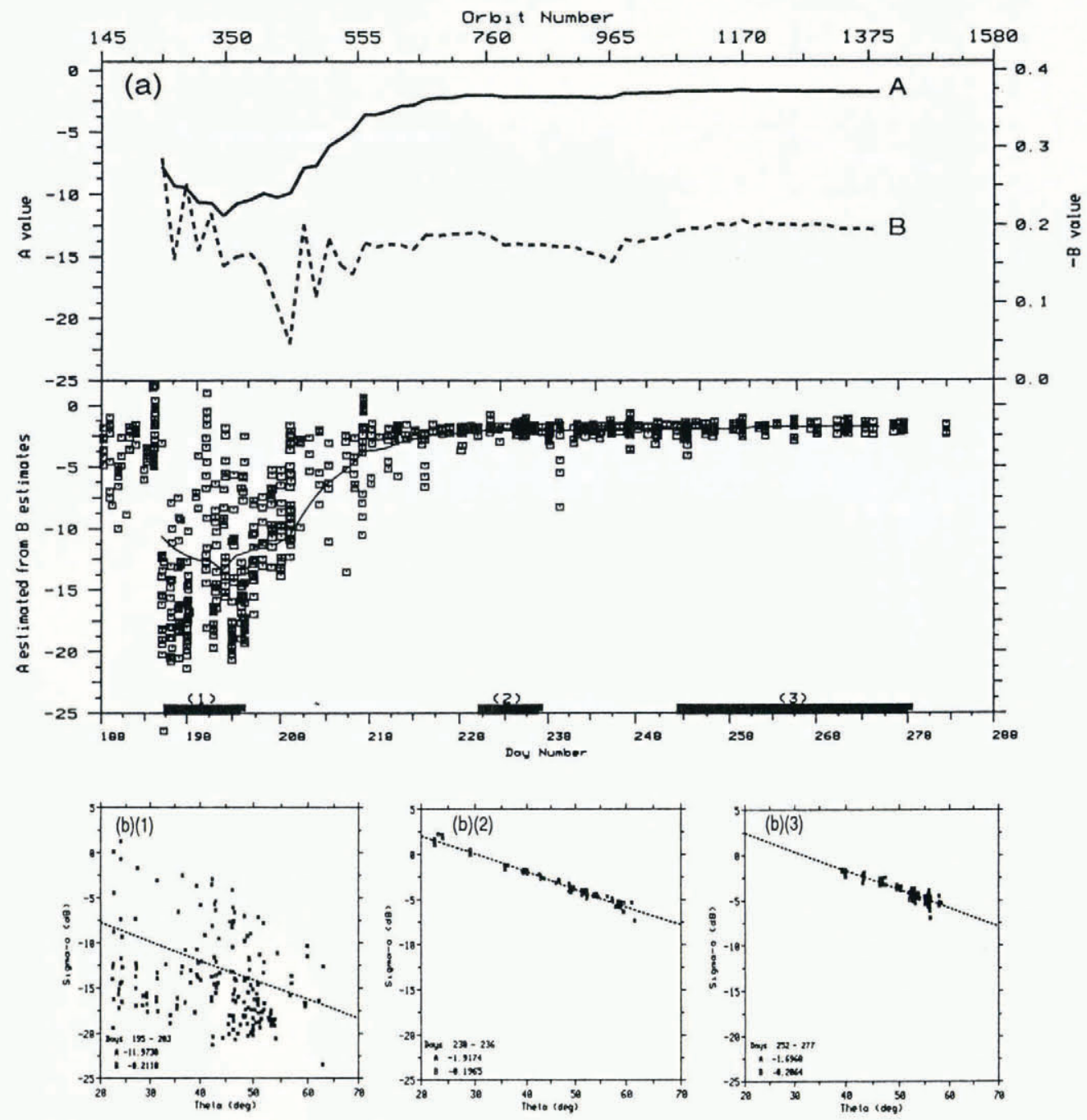

Fig. 3. (a) Plots of $A$ and $B$ for region $b$. (b) VV-polversus $\theta$ in region b for fulian days: (1) 195-203, (2) 230-236 and (3) 252-277.

of a more reflective or specular surface. This effect has also been identified in Ku-band altimeter data as dominant surface scattering (see figure $5 \mathrm{~b}$ in Partington and others (1989)), and occurs only during periods when melting is actively occurring at these elevations. The lowest-altitude samples, from region a (Fig. 2a), show the largest changes. Three significant periods relate to: (1) the mid-ablation season, (2) summer-fall transitional cooling (with bouts of remelting) and (3) stabilization with colder temperatures. These periods are further illustrated by the original data points in Figure $2 \mathrm{~b}$. The three panels show the significant temporal variation in $\sigma^{\circ}$ in region a, for periods (1)-(3).

Figure 3 presents plots of $A$ and $B$ and $\sigma^{\circ}$ versus time for region $b$ (Fig. 1). Figure $3 \mathrm{a}$ indicates a smoother timeseries than was apparent downslope (in Fig. 2). A clear minimum occurs in period (1), in which the peak melt causes values of $A$ around $-20 \mathrm{~dB}$. Significant scatter is observed during this melt period, due to the size of the window and the variability in surface properties and terrain over region $b$. The scatter in Figure $3 b(1)$ seems to indicate two populations of points, which it is suggested occur from patches of relatively wet and dry surfaces, similar to those observed by Jezek and others (1993). It is confirmed later that variability such as that seen in Figure $3 b(1)$, is due largely to spatial variability in the rates of surface change. Figure $3 \mathrm{~b}(2)$ and (3) include brief time windows during which $\sigma^{\circ}$ is relatively constant. We note increased $\sigma^{\circ}$ values and reduced scatter in the $A$ measurements as fall surface cooling progresses.

Region c data, shown in Figure 4a and b, illustrate that the further upslope, the less impact the summer melt has on the microwave signatures. Figure $4 b(1)-(3)$ show a relatively stable situation except for a departure in $\sigma^{\circ}$ due to a short-lived melt event at Julian day 197 in period (1). Subsequently, signatures stabilize. It appears that the further upslope one gets, the less the impact of summer temperatures upon the physical properties and resulting microwave signatures. Where no significant physical changes occur, we would expect to see negligible change in the $A$ and $B$ values extracted from the data. We will subsequently show that the delineation of the "dry-snow" zone becomes simple on the basis of no seasonal change.

\section{ENHANCED-RESOLUTION IMAGING TEGHNIQUE}

A recently developed technique for enhancing the resolution of scatterometer data can be used to create images of $\sigma^{\circ}$ at finer resolutions than the intrinsic resolution of the scatterometer data. The complete 


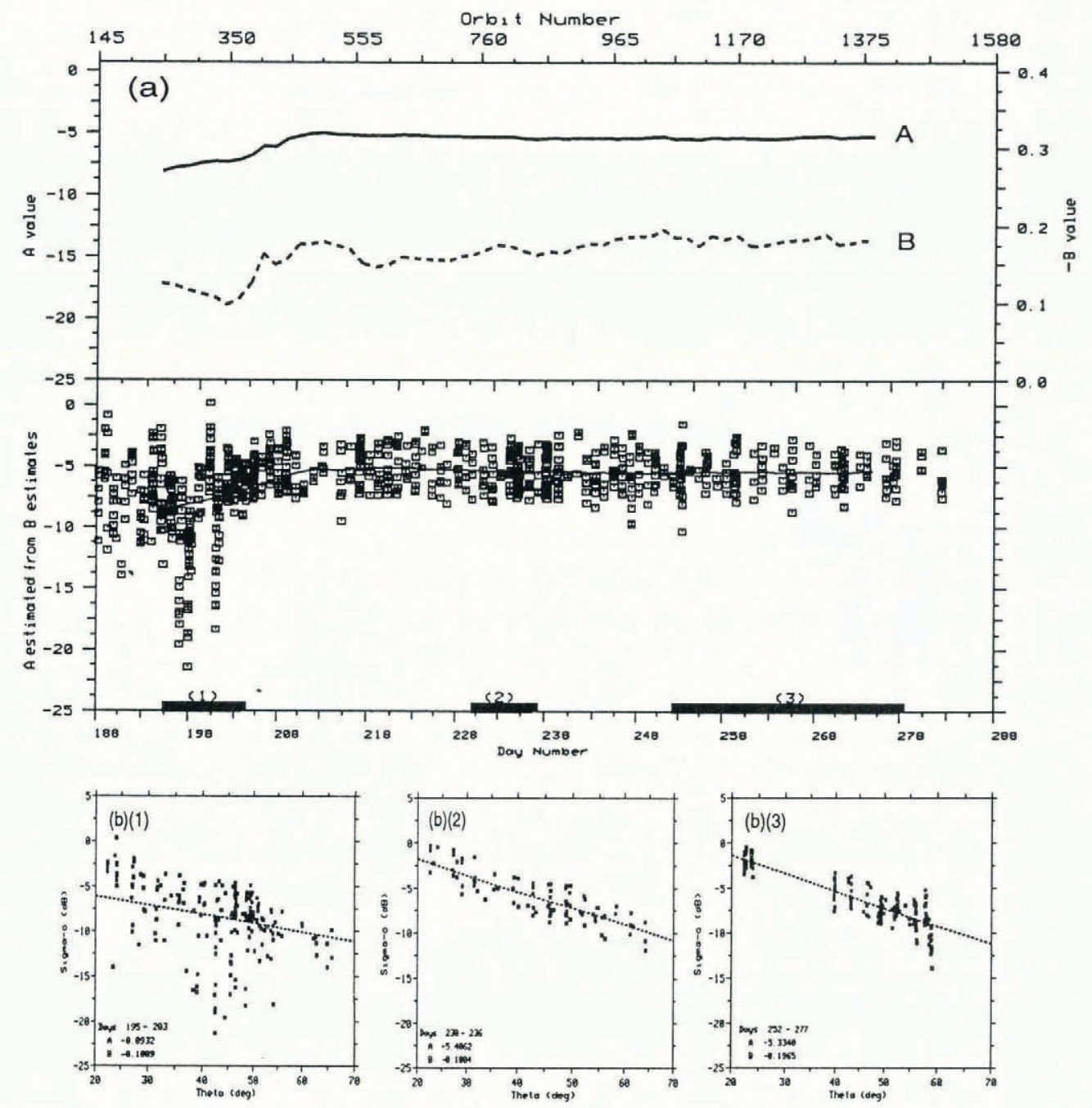

Fig. 4. (a) Plots of $A$ and $B$ for region c. (b) $V V-$ pol $\sigma^{\circ}$ versus incidence angle $\theta$ in region c for fulian days: (1) 195203, (2) 230-236 and (3) 252-277.

scatterometer image-reconstruction algorithm with filtering (SIRF) is described by Long and others (1993). This technique uses multiple, overlapping measurements of $\sigma^{\circ}$ and post-processing to improve the resolution. SIRF provides images of $A$ and $B$ with resolution up to $4-5 \mathrm{~km}$ from nominally $50 \mathrm{~km}$ resolution SASS data. However, in this study the image resolution was chosen to be $6 \mathrm{~km}$.

Resolution enhancement is not without cost; for instance, noise in the $A$ and $B$ images increases as resolution is increased. Hence, a trade-off is made between the resolution and the noise level. Furthermore, for SASS, multiple passes over the target are required to obtain sufficient measurement overlap. The resolution enhancement depends on the number of measurements, with greater numbers contributing to a reduced estimate of noise and/or improved resolution. However, during the "imaging-time interval" the radar characteristics must remain constant between passes. Some trade-off must therefore be made between imaging-time interval and resolution, due to temporal change. Additional requirements must be imposed and additional assumptions made regarding the $\sigma^{\circ}$ measurements. These are:

1. Instrument calibration must remain stable over the data-acquisition interval. SASS measurements of the Amazon rainforest (which exhibits little seas- onal variation) indicate calibration stability to be generally good $(0.4 \mathrm{~dB})$ (Bracalente and others, 1980).

2. $\sigma^{\circ}$ is assumed not to be a function of the azimuth angle of the measurement. As previously discussed, no significant azimuthal variation is observed in $\sigma^{\circ}$.

3. Surface topographic effects on the image-reconstruction process are assumed to be small and are therefore neglected. Surface slope modifies the local incidence angle and thus estimation of $A$ and $B$. However, $B$ is relatively small, typically $0.1 \leq$ $B \leq 0.22$ over Greenland. Since most of the Greenland ice-sheet is relatively flat on the $6 \mathrm{~km}$ resolution scale, and given the small value of $B$, this assumption is reasonable.

4. $A$ and $B$ should remain constant over the imaging time interval. For a sufficiently short interval this assumption is justified. However, in applying this method over Greenland, the interval must be of several days to weeks to obtain the measurement overlap required for the highest possible resolution.

We observe large long-term changes in $A$ and $B$ in some regions over the 3 month period (see Figs $2 \mathrm{a}$ and $3 \mathrm{a})$. The relative change in $\sigma^{\circ}$ over 1 to 2 weeks, however, 
is small. Hence, we restrict the imaging interval to 2 weeks with the resulting images reflecting the average surface response during this time period. Variations in $\sigma^{\circ}$ during this interval are treated as noise by the image-reconstruction algorithm. For example, short-term variability is observed at lower elevations (below the $0^{\circ} \mathrm{C}$ isotherm) along the fringes of the ice sheet. It is postulated that these changes are caused by melting and refreezing or simply precipitation events, since they occur at a frequency of several days, and are consistent with passing storms and low-pressure systems. These effects are averaged out in the high-resolution data.

In July, diurnal variations are expected along the icesheet periphery due to diurnal freeze/thaw cycles. Unfortunately, SASS provided limited time-of-day diversity, with measurements restricted to two times of day which varied with location. Careful studies of $\sigma^{\circ}$ as a function of time of day in several regions indicated no significant diurnal effects. This may be due to insufficient time-of-day diversity in the data. Thus, diurnal variations were not considered.

SASS $\sigma^{\circ}$ data span a range of $0^{\circ} \leq \theta \leq 70^{\circ}$; however, only measurements between $23^{\circ}$ and $55^{\circ}$ are used to create images in this study. For a given enhancedresolution element (pixel), $\sigma^{\circ}$ measurements spanning a sufficiently wide range of incidence angles are required to estimate $A$ and $B$. Over Greenland, pixels are generally observed with a wide diversity of incidence angles. In exceptional cases, an average $B$ value from the mission lifetime is assigned to the pixel. The resulting error in the $A$ estimate is generally less than $1 \mathrm{~dB}$. Measurements with excessive noise (i.e. those with normalized standard deviations greater than $15 \%$ ) are not used in the imaging process. Data from orbits with large spacecraft altitude errors were also rejected. Long and others (1993) give a further discussion of SASS data anomalies and error filtering.

\section{GREENLAND IMAGE TIME-SERIES}

Using vertically polarized (VV) SASS $\sigma^{\circ}$ measurements and the SIRF algorithm, a time-series of $A$ and $B$ images of Greenland is generated. Separate $A / B$ image pairs, shown in Figure 5, describe each 2 week period of the 3 month mission. In this time-series, $A$ images have approximately $6 \mathrm{~km}$ resolution. Though $B$ images have $6 \mathrm{~km}$ resolution pixels, their actual resolution is not quite this high since a $3 \times 3$ spatial smoothing filter is applied in the SIRF algorithm. In addition, for some pixels it was not possible to estimate the $B$ value since the $\sigma^{\circ}$ measurements covering the pixel did not span a sufficiently wide range of incidence angles. This reduces the effective resolution of the $B$ estimate.

Seasonal variation is clearly evident in Figure 5, with a large change in $A$ along the ice-sheet periphery attributable to the progression in the extent and influence of the melt zone in summer. In early July, during the height of the ablation season, the black swath around western and southern Greenland corresponds to surface melt. The lower limit of this dark swath corresponds with the zone of wet, bare ice of the ablation zone near the icesheet fringe. The upper limit corresponds to the transition from wet-snow to percolation facies (i.e. the wet-snow line). By definition (Williams and others, 1991) the wetsnow line has no obvious surface manifestation; however, microwaves can sense water-laden snow effectively. In the sequence shown in Figure 5, as the fall freeze-up takes

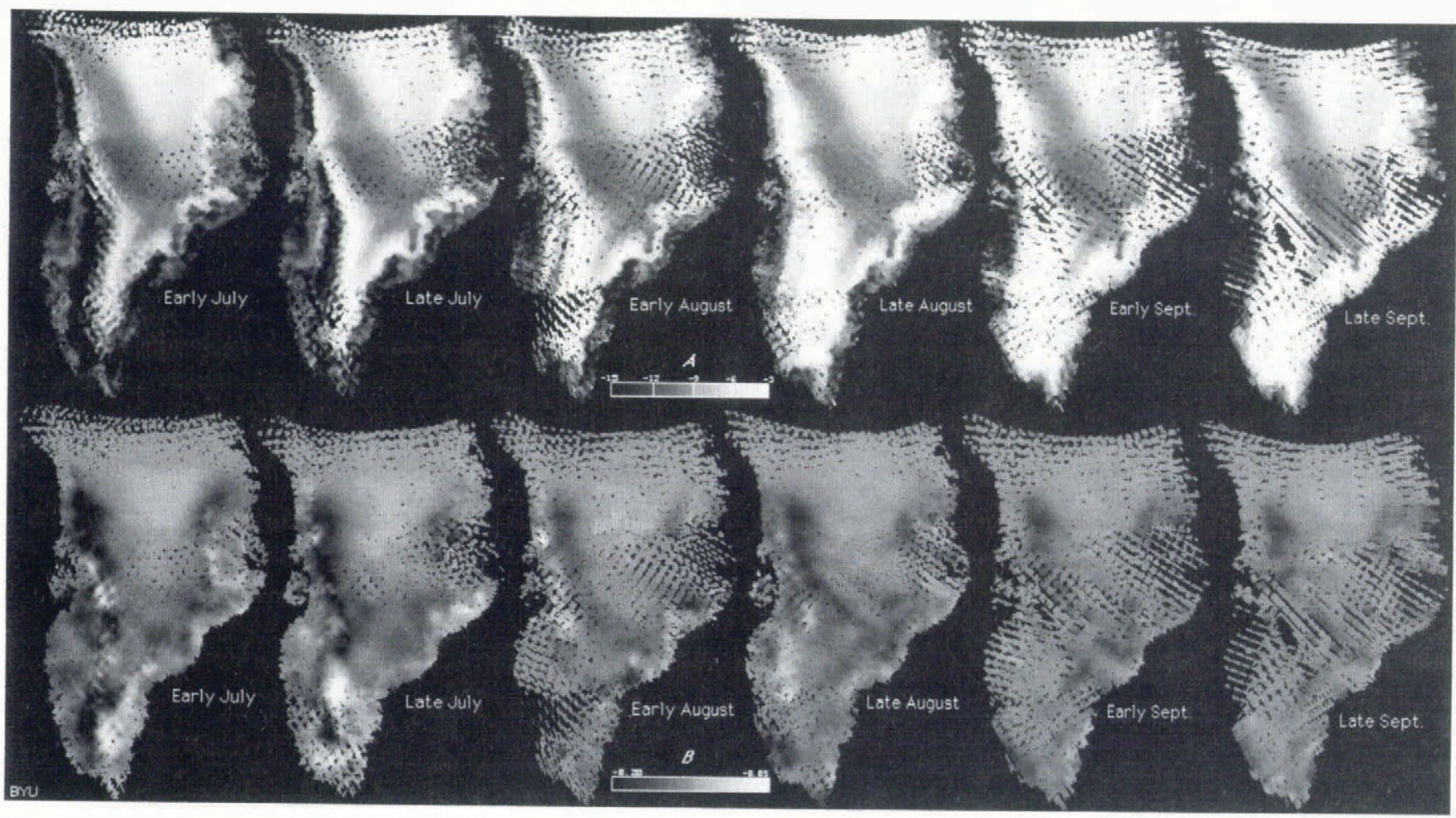

Fig. 5. Time-series of $A$ (upper) and B (lower) images (VV-pol), one for every 2 weeks of the 3 month SASS mission. Each image is generated from approximately 2 weeks of vertically polarized $\sigma^{\circ}$ measurements in early $\mathrm{July}$, late $\mathrm{July}$, early August, late August, early September and late September. 
place, from mid-August onwards, the original wet-snow and percolation zones coalesce to become a bright band of extremely high back-scatter. Normalized $A$ values at $40^{\circ}$ incidence are close to $0 \mathrm{~dB}$ in the percolation zone. Notably, by late September the upslope limit to the percolation zone is well defined and is mapped as a dramatic fall of several $\mathrm{dB}$ while crossing into the invariant dry-snow regime. Bright areas mark the limit of summer melting on the ice sheet, and effectively the dry-snow line.

The dry snow of central Greenland exhibits relatively high $\sigma^{\circ}$ and negligible temporal change. However, Figure 5 indicates large spatial variability, correlating well with annual snow-accumulation maps. For example, the highest annual accumulation of solid precipitation, with over $50 \mathrm{~cm}$ of water equivalent (w.e.) occurs just east of the Jakobshavns Isbræ. Mean values of $A$ in this area are $-11.93 \pm 0.75 \mathrm{~dB}$, but drop gradually up to the summit, as accumulation falls to around $25 \mathrm{~cm}$ w.e. (Ohmura and Reeh, 1991). Notably, the largest dry-snow $A$ values occur in the northeast, with a mean of $-4.02 \pm 0.22 \mathrm{~dB}$. Though not the highest elevation of the ice-sheet, the northeastern catchment area is in the precipitation shadow of the major ice divides. The consequence is annual accumulation of only $10 \mathrm{~cm}$ w.e.

The accompanying maps of $B$ indicate the slope of $\sigma^{\circ}$ with incidence angle. During the early period, when melting is predominant on the warmest slopes along the ice-sheet fringes, the high values of $B$ probably indicate that surface scattering dominates back-scattering. Very negative values of $B$, of around $-0.2 \mathrm{~dB} \mathrm{deg}^{-1}$, indicate smooth surface scatterers with a high dielectric constant. Concentrated regions of low gradients with $B$ close to $-0.05 \mathrm{~dB} \mathrm{deg}^{-1}$ indicate localized snowfall, rougher surfaces where the $A$ values are relatively high (such as the southeastern percolation zone in early July), or that there is a large scatter in the values of $\sigma^{\circ}$ with incidence angle (owing to high spatial variability in surface properties in the resolution cell). Ohmura and Reeh (1991) noted summer snowfall on the western flank of the ice-sheet above $2200 \mathrm{~m}$. Some of the low-gradient bright patches may reflect such precipitation. Previous normalincidence observations at $\mathrm{Ku}$-band by Partington and others (1989) also indicate strong evidence for the dominance of surface scattering south of $68^{\circ} \mathrm{N}$. This supports the observation that roughness and dielectric constant of the surface are the main modulators of the observed signatures in this region.

$B$ appears particularly sensitive to variability in scattering mechanisms, especially in regions where variability in $\sigma^{\circ}$ is large. This happens in the ice margins where ablation is occurring due to the spatial inhomogeneity in the surface types. With fall cooling, the variability in $B$ disappears. Such a situation is characteristic of the reduced dominance of surface scattering as cooling progresses. Values of $B$ then tend toward those observed in regions where volume-scattering is known to dominate, as in the dry-snow zone to the north. By the last two weeks in September, $B$ has very little variability throughout the ice-sheet (Fig. 5).

Further detailed analysis of these images is deferred until section 7. In the following section we compare the SASS-derived $A$ and $B$ images with data from airborne scatterometers and synthetic aperture radars (SARs) in order to substantiate and validate the data values derived using the high-resolution imaging technique.

\section{IMAGE VALIDATION}

In this section we briefly compare images derived using the SIRF algorithm on SASS data with airbornescatterometer and synthetic aperture radar (SAR) image data. This approach is used to validate the techniques used in image rendering, as well as the utility of the derived products such as $A$ and $B$.

\section{Comparison with airborne-scatterometer measurements}

Swift and others (1985) analyzed airborne Ku-band (14.6 $\mathrm{GHz}$ ) scatterometer data acquired over southern Greenland on 14 October 1979. They measured $\sigma^{\circ}$ at several incidence angles from $0^{\circ}$ to $60^{\circ}$ and at $\mathrm{VV}, \mathrm{HH}$, and cross-polarizations along a transect across southern Greenland (see Fig. 1). Their VV-pol plot, reproduced in Fig. 6a, was collected from east to west along transect $d$
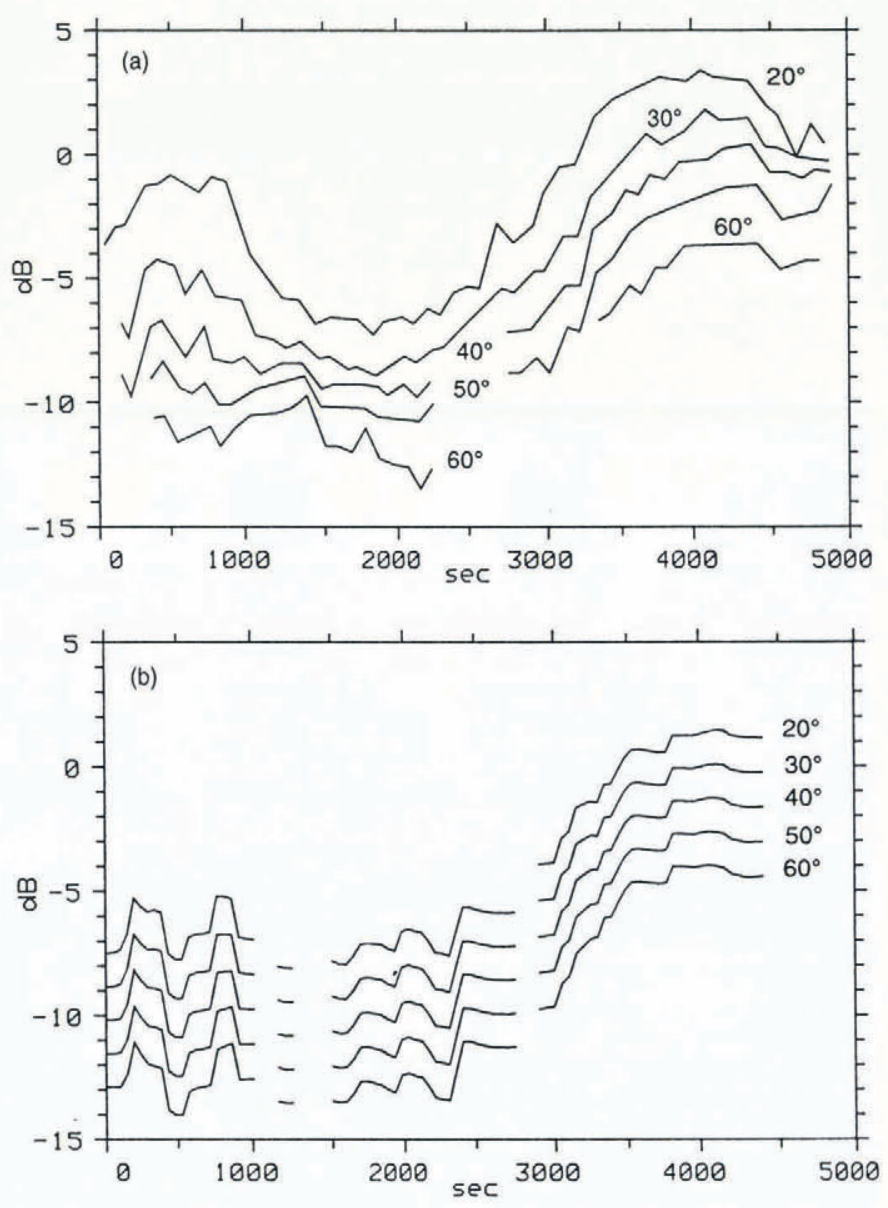

Fig. 6. Comparison of $\mathrm{VV}$-pol $\mathrm{Ku}$-band $\sigma^{\circ}$ versus time along the aircraft transect shown as $d$ in Figure 1. (a) Reproduction of figure 5 of Swift and others (1985) showing $\sigma^{\circ}$ at several incidence angles. (b) Comparison of $\sigma^{\circ}$ versus time computed from the SASS-derived $A$ and $B$ images in Figure 5 (late September) at similar incidence angles. 
shown in Figure 1. Figure $6 \mathrm{~b}$ presents VV-pol SASS at $\sigma^{\circ}$ incidence angles from $20^{\circ}$ to $60^{\circ}$ along the same line, taken from SASS-derived late September $A$ and $B$ images. Although Figure $6 \mathrm{~b}$ corresponds to a 2 week average earlier in the season and a year prior to the Swift and others' (1985) flight, it compares very favorably with Figure $6 \mathrm{a}$. The same general features and $\sigma^{\circ}$ values are evident, although the $\theta$ dependence of $\sigma^{\circ}$ is linearized in the SASS-derived plots by assumptions used in the derivation of $A$ and $B$. Notable features apparent in both Fig. $6 \mathrm{a}$ and $\mathrm{b}$ are the small bump between 500 and $1000 \mathrm{~s}$, together with the profile step between 2000 and $3000 \mathrm{~s}$ along the flight line. We conclude, therefore, that application of the resolution-enhancement algorithm to SASS data provides the desired $6 \mathrm{~km}$ resolution while preserving the key back-scatter characteristics.

\section{Comparison with SAR data}

For further evaluation of the enhanced-resolution SASS images we use synthetic aperture radar (SAR) data from Seasat and aircraft. Differences between these SAR data and the SASS data include radar frequency, measurement integration time and the coverage and resolution. In addition, the aircraft SAR data were acquired over a decade after the Seasat data, in August 1989 (Jezek and others, 1993), by the Jet Propulsion Laboratory (JPL) airborne polarimetric radar.

Airborne-SAR comparison data were collected at P-(0.4 GHz), L- $(1.2 \mathrm{GHz})$ and C-bands $(5.3 \mathrm{GHz})$, in contrast to the $\mathrm{Ku}$-band $(14.6 \mathrm{GHz})$ SASS data. In general, the higher-frequency SASS has less penetration into the ice and firn, particularly in the presence of liquid water. In effect, the different frequencies look at slightly different portions of the upper ice sheet. Previous work using normal incidence $\mathrm{Ku}$-band altimeter ice-sheet returns (Ulander, 1985; Drinkwater, 1987; Partington and others, 1989) has shown that the penetration does depend upon the season and geographic location in relation to the major snow and ice facies.

A key difference between SAR and SASS data is the measurement integration time. SAR data represent an essentially instantaneous measurement in contrast to the 2 week-average SASS images used here. Thus, SASS images average out short-term temporal variations. On the other hand, because the SASS data is available over several months, it is possible to examine seasonal variations over broad regions. In addition, though the JPL aircraft SAR provides high resolution $(10-30 \mathrm{~m})$, it covers only a $12 \mathrm{~km}$ swath. Scatterometer images provide only medium-scale resolution $(6 \mathrm{~km})$ but cover the entire ice-sheet up to about $78^{\circ} \mathrm{N}$. In effect, SASS images trade resolution for coverage and integration time.

At the end of August 1989, JPL flew a multi-band SAR over a $90 \mathrm{~km}$ transect across the ablation zone (see Fig. 1; transect e) in southwestern Greenland. Jezek and others (1993) collected P-band, L-band, and C-band imagery along a $12 \mathrm{~km}$ wide track. They compare this data with imagery collected by the L-band $(1.2 \mathrm{GHz})$ Seasat satellite-borne SAR in early October 1978. To aid in comparison, a plot of spatially averaged $\sigma^{\circ}$ from the C- and L-band airborne data and the L-band Seasat data was prepared. A 10 pixel (approx. $70 \mathrm{~m}$ ) wide swath down the center of the airborne-SAR data $\left(\sim 43^{\circ}\right.$ incidence) was extracted. Pixels along the same track were extracted from the Seasat SAR images (see Jezek and others, 1993). Values in a $10 \mathrm{~km}$ long moving window were then averaged (to simulate the resolution of the SASS data) and plotted in Figure 7a, although the crosstrack resolution is only approximately $70 \mathrm{~m}$. The SASS curve is a plot of $A$ of along the aircraft transect.

Along-track results shown in Figure 5 begin in the percolation zone and end in the wet-snow zone. Backscatter variability near the end of the track is due to morphological features and patchy slush areas near the ice-sheet margin (Jezek and others, 1993). An important conclusion from Figure $7 \mathrm{a}$ is that the value of $A$ observed at $10 \mathrm{~km}$ resolution is critically dependent on the precise location of the center of the $6 \mathrm{~km}$ resolution element with
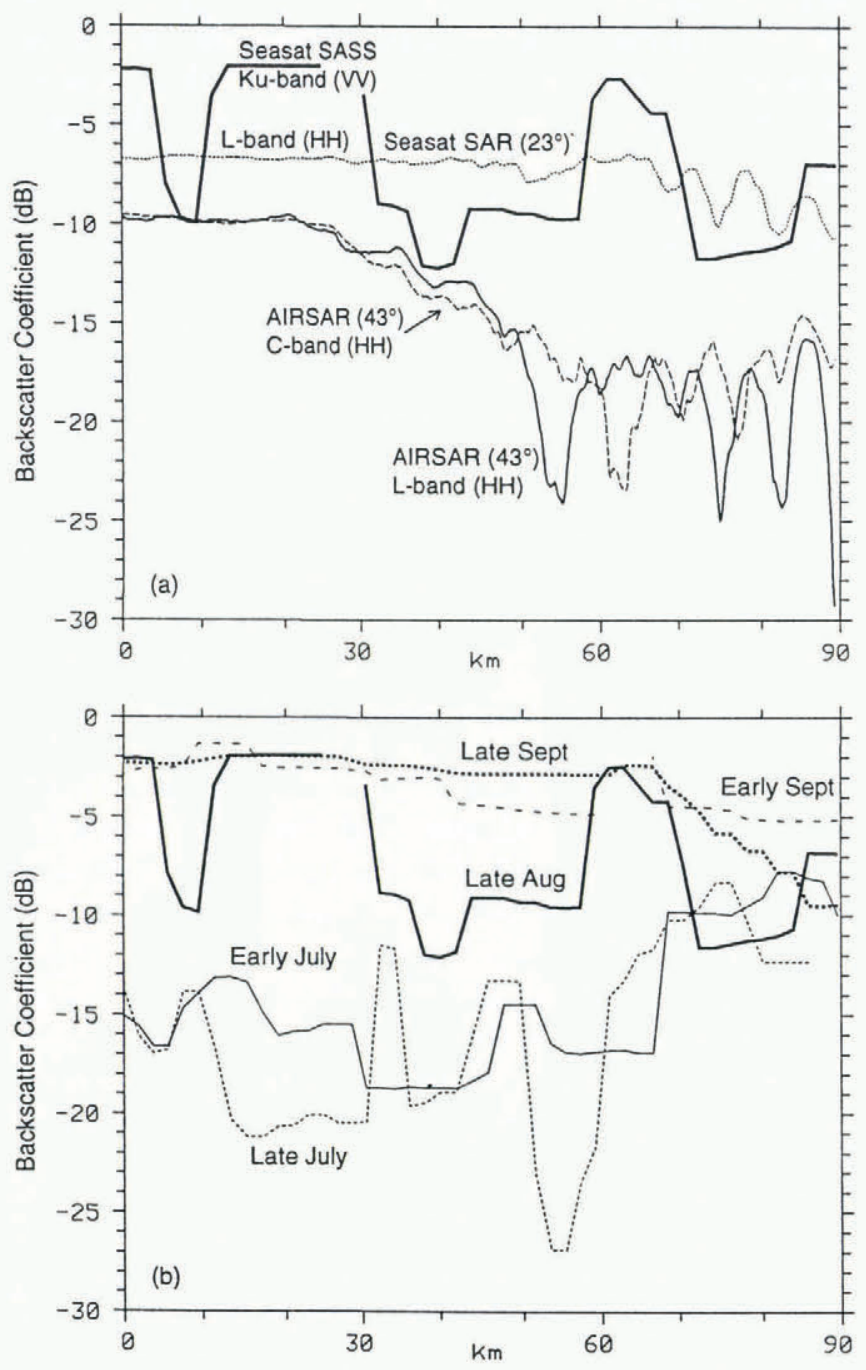

Fig. 7. Plots of $\sigma^{\circ}$ with distance along transect $e$ in Figure 1. (a) Values of $\sigma^{\circ}$ derived from SEASAT Kuband SASS and L-band $H H$-pol SAR data and $L$-band and $C$-band $H H$-pol AIRSAR data. Original SAR data from Jezek and others (1993) are smoothed using a $10 \mathrm{~km}$ moving window. Superimposed are SASS data from the late August period, to correspond with the AIRSAR time window. (b) Plots of $A$ from each of the 2 week images in Figure 5. An early August transect is not included due to the lack of adequate coverage of SASS along the transect line during this time period. 
respect to snow or ice facies or mixed surfaces near the icesheet periphery. Differences between them are attributed primarily to the pixel scale and measurement integration as well as the difference in imaging years. Further differences may be attributed to sampling variability.

Figure $7 \mathrm{~b}$ illustrates change along the transect over the 3 months of the Seasat SASS mission. We note from Figure $7 \mathrm{~b}$ that $A$ changes rapidly between summer and fall. Seasonal variation in $A$ accounts for more than $20 \mathrm{~dB}$ change over the period shown. The minimum values $(<-20 \mathrm{~dB})$ occur in July during peak melt but, as time progresses, the wet-snow zone becomes as bright as the percolation zone, with values of about $-3 \mathrm{~dB}$.

\section{SNOW-FACIES IDENTIFICATION AND MODEL SIMULATIONS}

Here we analyze the SASS data from a number of different regions shown in Figure 1. In conjunction, we describe results from a parametric-model study to illustrate the effects of spatial and temporal variability in surface properties upon the microwave back-scatter signatures.

\section{Dry-snow zone}

The definition in sensu stricto of this zone is the region above the dry-snow line, where negligible melting or percolation takes place (Benson, 1962). The mean climatological July air temperature at summit is around $-10^{\circ} \mathrm{C}$, and as one moves downslope to the north and west it increases to between $-5^{\circ}$ and $0^{\circ} \mathrm{C}$. Ohmura and Reeh (1991) demonstrated that annual accumulation in the dry-snow zone is closely dependent on precipitation patterns and wind patterns across the ice-sheet. Lower accumulation to the north and east and the patterns observed in Figure 5 support the observation that the topographic barrier imposed by the western flank of the ice cap to the predominant winds from the southwest results in a significantly different microwave scattering situation in the northeast. A line can be drawn in our Figure 5 along the western edge of the bright zone to the northwestern corner of the plots which closely follows that drawn by Ohmura and Reeh (1991) in their figure 5. The following discussion treats the differences in the microwave scattering between these distinct dry-snow regimes.

\section{Northern and northeastern region}

To the northeast, where the snow accumulation is lowest, we observe the highest values of dry-snow $\sigma^{\circ}$ (see Fig. 5). Figure 8 shows the SASS time-series from region $\mathrm{f}$ in Figure 1, using the same presentation as in Figure 2. Figure 8a shows $A$ values around $-5 \mathrm{~dB}$ and low $B$ values around $-0.1 \mathrm{~dB} \mathrm{deg}^{-1}$. Values of $A$ have an extremely low variance while Figure $8 \mathrm{~b}$ shows a distinct roll-off in the values of $\sigma^{\circ}$. These results illustrate the lack of seasonal variation in the dry-snow zone during the $100 \mathrm{~d}$ period. Between Julian days 188 and 208, when surface temperatures are warmer, dielectric loss $\left(\epsilon^{\prime \prime}\right)$ in the snow rises, increasing electromagnetic absorption. Cooling, between Julian days 218 and 278 , causes a small yet perceptible steady rise in $A$ from -5 to $-4 \mathrm{~dB}$ by early October, due to the small reduction in loss.
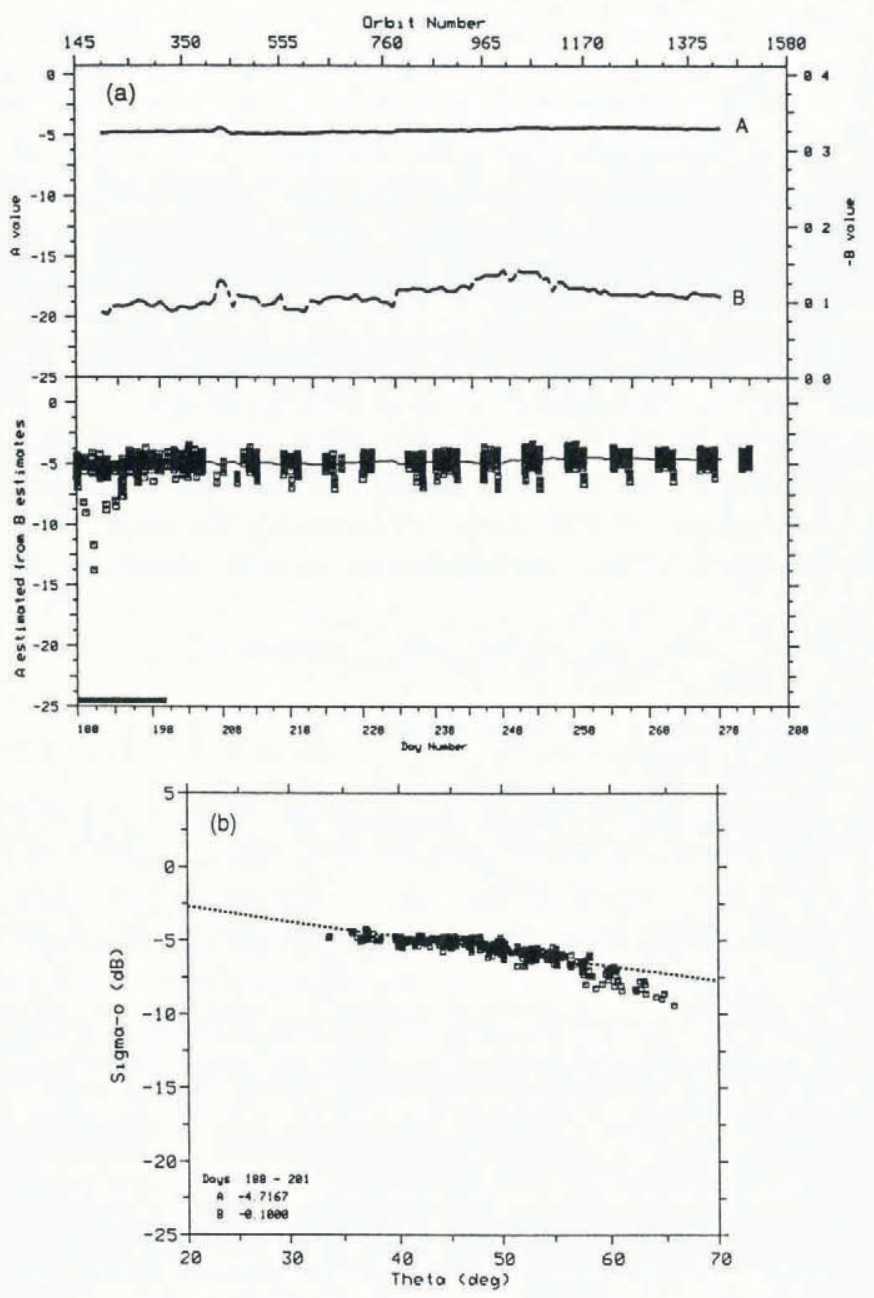

Fig. 8. (a) Plots of $A$ and $B$ for the $1^{\circ} \times 2^{\circ}$ study region $f$ in the northern dry-snow zone. The plots were computed using the same technique as described for Figure 2. (b) $\sigma^{\circ}$ versus $\theta$ plot for days 188-201 in region $f$.

Annual snow accumulation in the northeast is as low as $10 \mathrm{~cm} \mathrm{year}^{-1}$ water equivalent (w.e.), increasing gradually southwards towards the summit (at $3233 \mathrm{~m}$ ). $\sigma^{\circ}$ decreases correspondingly from $A=-4.72 \mathrm{~dB}$ to $-10.63 \mathrm{~dB}$, with a slight increase in $B$ from -0.1 to -0.16 (see Fig. 5). The trend mirrors the change in annual precipitation totals for these geographic locations, with the consequence that the depth of the former summer surface is shallower in the northeast of the ice-sheet. This has an important impact, with surface scattering from the wind-packed firn, or vapor-transport horizon beneath the fresh snow layer, entering into the back-scattering process.

A simple physical model (see Fig. 9) is specified, which takes into account the two primary layers involved in radar scattering (see Drinkwater, 1989; Livingstone and Drinkwater, 1991; Winebrenner and others, 1992). These are an upper layer of annual snow accumulation, upon an infinite layer of firn or ice, often with a thin upper layer of wind-slab. Both snow and buried wind-slab surfaces have roughness values specified by typical laser-measured snow surfaces (Rott and others, 1985; A. Carlstrom, personal communication). The layer parameters are specified, based upon typical field-measured values taken from Benson (1962) and Williams and others (1991), together 


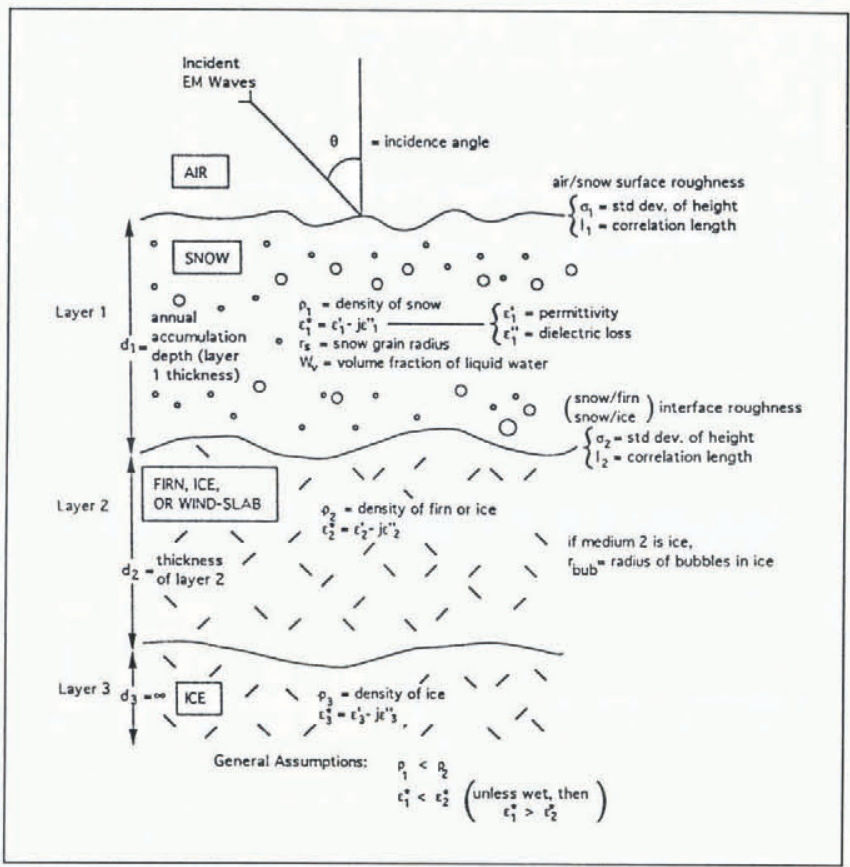

Fig. 9. Description of simple 2 layer physical model used in the simulation of microwave back-scattering. Implicitly, layer 0 is air. Layer 1 is snow or firn and layer 2 is a stratigraphic horizon corresponding with relatively dense snow, iced firn or glacial ice. The parameters are given in the legends of subsequent model simulations.

with annual accumulation estimates from Ohmura and Reeh (1991). Dry snow is effectively transparent to microwaves so there is little or no scattering at the air/ snow boundary and consequently back-scatter is determined by the volume scatter intensity. In the northeast, the snow depth and snow grain radius have the most important influence upon the volume-scatter.

Model simulations of back-scatter from region $f$ indicate that volume-scatter from an infinite Rayleigh layer of fresh snow can only give a $\sigma^{\circ}$ value of about $-15 \mathrm{~dB}$ at $40^{\circ}$. To augment this value, in order to match the brighter observed returns with the level and gradient observed, we must either assume unrealistically large snow grains or add a distinct horizon beneath the annual layer of accumulated snow. Obviously, in relatively transparent dry snow, surface scattering from the firn beneath (of a typical density of $0.4 \mathrm{Mg} \mathrm{m}^{-3}$ ) is significant. It is hypothesized that this effect causes the brighter signature observed in the northeast. Supporting this argument is the fact that $\sigma^{\circ}$ between $30^{\circ}$ and $60^{\circ}$ does not decline at the rate for typical volume-scatter. Hence, surface scattering from this sub-surface layer is required to explain the observed values.

A model simulation result is shown in Figure 10 for a typical annual accumulation depth of $17.5 \mathrm{~cm}$ w.e. (i.e. $53 \mathrm{~cm}$ snow at a typical mean density of $0.33 \mathrm{Mg} \mathrm{m}^{-3}$ ). The dry-snow surface roughness is unimportant in the observed curves, since the transmissivity at the surface is high. To fit the value of the volume-scatter at $65^{\circ}$, a typical mean snow-grain radius of $0.5 \mathrm{~mm}$ was used together with the permittivity $\left(\epsilon^{\prime}\right)$ and loss $\left(\epsilon^{\prime \prime}\right)$ for this density at a temperature of $-10^{\circ} \mathrm{C}$ (Tiuri and others, 1984). A denser snow layer was used for layer 2 , which

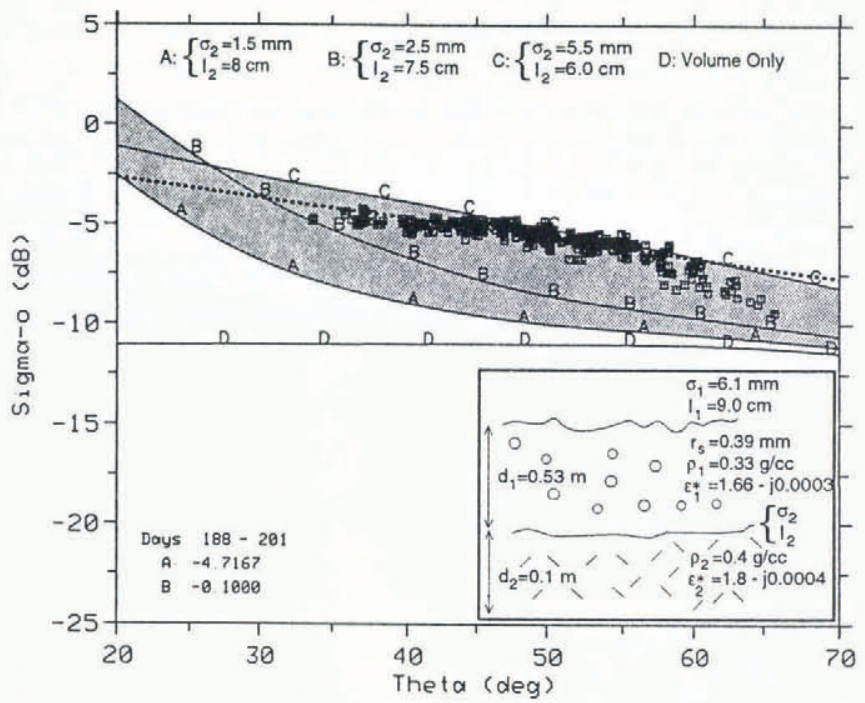

Fig. 10. Plot of $\sigma^{\circ}$ versus $\theta$ for a simulation example corresponding to a simple 2 layer model for the northern $d r y$-snow zone in region $f$, Figure 1 , with the data from Figure $8 b$ superimposed. The inset describes the layer properties used as model inputs. The shaded region suggests the simulated back-scatter regime bounded by extremes for high and low sub-surface roughness values.

corresponds with the layer described by Benson (1967), to represent a stratigraphic discontinuity. The roughness of the upper surface of this boundary is specified by typical laser-measured values and shown in Figure 10. The shaded zone in Figure 10 encompasses the area in which the points from Figure $8 \mathrm{~b}$ fall. The upper and lower bounds of this shaded area are specified by the roughest (C:) and smoothest (A:) surface roughnesses. Points from Figure $8 \mathrm{~b}$ fall close to curve $\mathrm{C}$ for a rough surface. The statistics indicate a root-mean-square $(\mathrm{rms})$ surface height of $5.5 \mathrm{~mm}$ and a correlation length of $6 \mathrm{~cm}$.

\section{Western flank and summit region}

At the summit, mean summer temperatures of below $-10^{\circ} \mathrm{C}$ are experienced, together with higher annual accumulation of $30 \mathrm{~cm}$ w.e or an equivalent of $100 \mathrm{~cm}$ of snow at a density $(\rho)$ of $0.3 \mathrm{Mg} \mathrm{m}^{-3}$. Benson (1962) presents results from over 100 snow pits in the dry-snow zone at high altitude on Greenland. Lower mean summer air temperatures lead to slower grain growth and grain diameters of less than $1 \mathrm{~mm}$. Typical densities in the first annual unit are in the range of $0.25-0.35 \mathrm{Mg} \mathrm{m}^{-3}$, with a mean close to $0.3 \mathrm{Mg} \mathrm{m}^{-3}$. In summary, there is a deeper light-snow layer with a smaller mean grain-size than in the northern region but resting upon firn of similar density to the northern dry-snow region.

Comparisons between the data and model simulations suggest differences with the northeastern dry-snow zone. In order to simulate the $-16 \mathrm{~dB}$ value of $\sigma^{\circ}$ at $65^{\circ}$, the effective depth of the snow (i.e. layer 1) or the grain diameter must be reduced relative to the Figure 10 example. This reduces the proportion of the total backscatter contributed by Rayleigh volume-scattering. However, since annual accumulation is actually higher, the increment in volume-scatter due to deeper snow must be offset by a reduction in mean grain-size. Because grain- 
size is the primary influence upon the Rayleigh volumescattering contribution, a reduction in diameter of only $0.16 \mathrm{~mm}$ is required to offset greater snow depths of up to $1 \mathrm{~m}$. With a mean grain diameter of $0.23 \mathrm{~mm}$ and a snow depth of $1 \mathrm{~m}$ (at $\rho=0.33 \mathrm{Mg} \mathrm{m}^{-3}$ ), the total volumescattering background level is around $-15 \mathrm{~dB}$. This is the level observed in Figure 11 at $65^{\circ}$. Thus, high incidence $\sigma^{\circ}$ values have fallen by several $\mathrm{dB}$ from those plotted in Figure $8 \mathrm{~b}$.

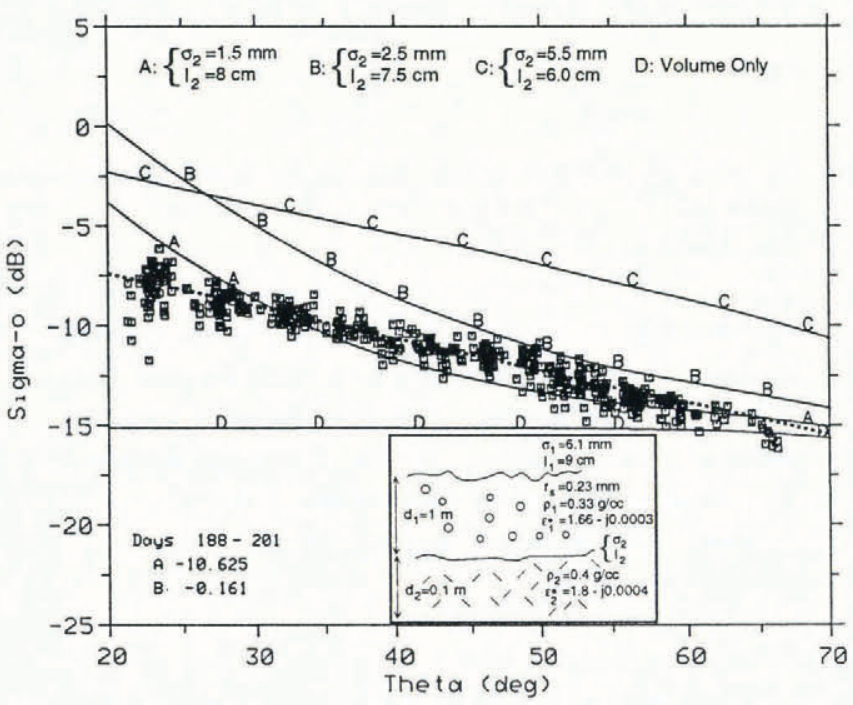

Fig. 11. Plot of observed back-scatter signature from region $g$, Figure 1, overlaid with the results of a simulation example corresponding to a simple 2 layer model for the southern-summit dry-snow zone. The inset describes the layer properties used as model inputs. Air/snow and snow/ ice interface roughness was scaled using typical published field data obtained from laser measurements.

Figure 11 presents a comparison of the SASS backscatter and simulated data for the southern summit (centered at $70^{\circ} \mathrm{N}, 38.5^{\circ} \mathrm{W}$ ) between days 188 and 201. Annual accumulation at the southern summit is greater than that to the north, and yet $A$ is lower than in Figure $8 \mathrm{~b}$. Additionally, $B$ is -0.16 and is larger than to the north. The model result for the summit in Figure 11b indicates that if all parameters except grain-size and snow depth remain the same, then $\sigma^{\circ}$ falls within the simulated range. Figure 11 shows that the data fall between curve $B$, for medium-rough, and A, for smooth layer 2 surfaces. This result appears to indicate that the roughness of the underlying summer surface (firn or wind-slab) is not as large as is observed in the northeastern dry-snow region, otherwise the value of $B$ would be smaller.

For contrast, in Figure 12 another example is shown for the same time period as Figure 11. It is taken from sample window $\mathrm{h}$ in Figure 1 from the northwestern drysnow zone. These data indicate a similar pattern to that observed at the southern summit and are intentionally selected from a locality where Ohmura and Reeh (1991) record a $30 \mathrm{~cm}$ w.e. mean annual accumulation. It may be concluded from this that dry-snow regions with similar temperature and accumulation regimes give consistent microwave signatures.
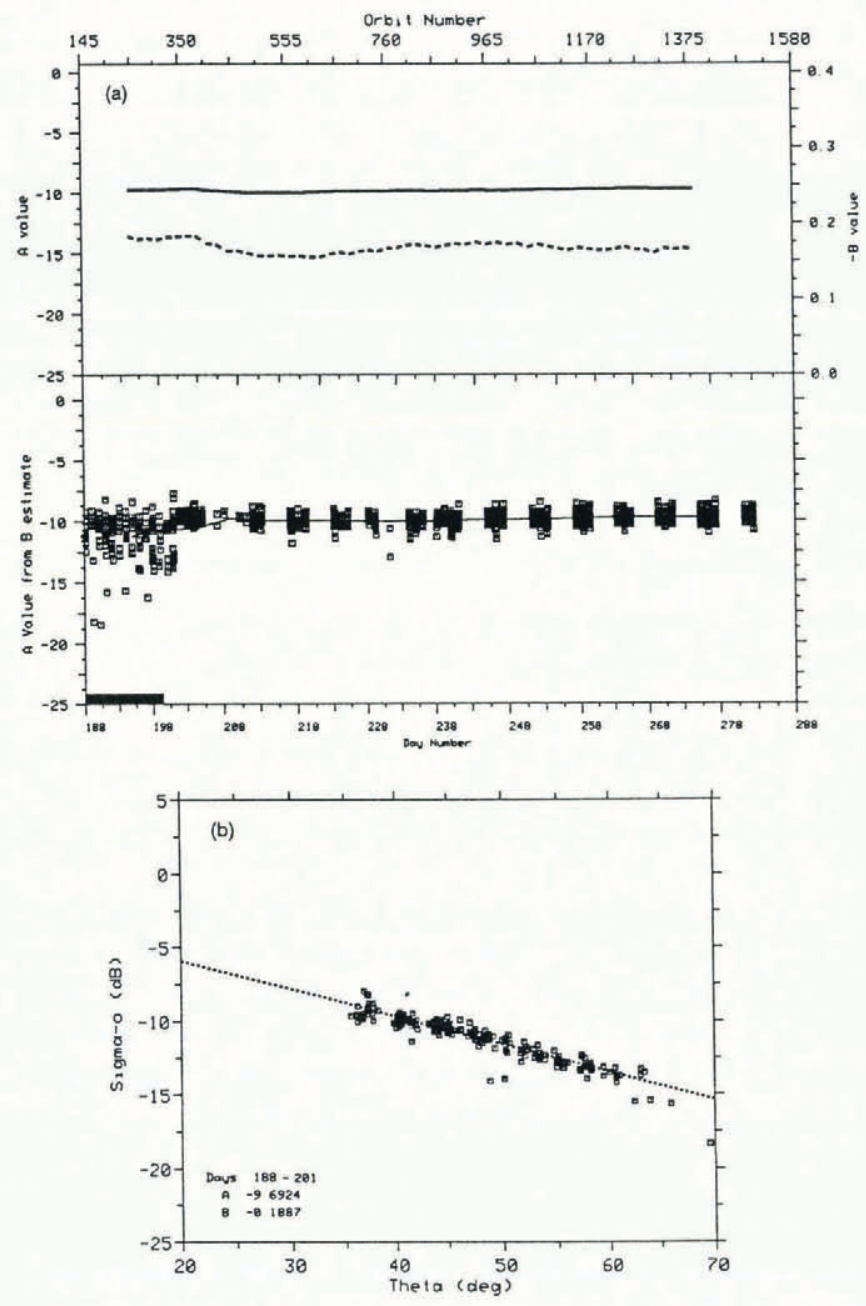

Fig. 12. (a) Time-series of $A$ and $B$ for region $h$ centered at $75.5^{\circ} \mathrm{N}, 49.5^{\circ} \mathrm{W}$. (b) $\sigma^{\circ}$ versus $\theta$ plot for days 188-201 in the same northwest dry-snow area.

\section{Dry-snow summary}

The nature of the dry-snow zone back-scatter essentially does not change temporally, except for small variations due to upper-snow warming in mid-July. Modeling simulations demonstrate that, even in the areas of the deepest dry-snow cover, the snow is largely transparent and the primary source of back-scatter is a combination of surface scattering from the summer surface and Rayleigh scatter from the snow volume.

If all snow characteristics could be assumed to be homogeneous throughout the dry-snow zone, the depth of annual accumulation would have the greatest influence upon observed patterns of back-scatter, with larger values of $A$ as annual solid accumulation increases from 10 to $50 \mathrm{~cm}$ w.e. southwestwards across the zone of dry snow. However, instead of the back-scatter increasing as annual accumulation increases, the opposite trend takes place. The lowest dry-snow $A$ values occur in the area of 40 $50 \mathrm{~cm}$ w.e. accumulation on the western flank of the ice sheet to the east of Jakobshavns Isbra. This effect requires further explanation: model simulations suggest that varying snow grain-size and density, together with the roughness of the summer surface beneath the annual accumulation, can account for this discrepancy. These variations result in a total change in $A$ of around $8 \mathrm{~dB}$ 
within the dry-snow zone. These observations correspond with results of recent comparisons of SASS with ERS-1 data (Jezek and Gogineni, 1992), where similar trends are identified in the Greenland SAR data. On the basis of snow grain-size alone, this would require a change in mean grain radius of $0.25 \mathrm{~mm}$, which is extremely unlikely. Similarly, within the typical range of observed density and depth, this variability cannot be reproduced. Thus, to explain these results, further field measurements are required to describe the characteristics of the summer surface beneath the annual snow accumulation. One suggested hypothesis is that the small-scale surface roughness associated with wind-scouring of the previous summer surface or wind-slab may become significant where there is relatively low accumulation. The interface roughness is a predominant feature required in the scattering simulations from this zone.

The dry-snow zone may clearly be divided into two regions on the basis of the observed signatures and model simulations. These are: (i) the region (dry snow I) found to the north and northeast, comprising the relatively lower-elevation region in the precipitation shadow of the main ice-sheet topographic barrier; and (ii) the summit or higher-accumulation dry-snow region (dry snow II), where mid-summer mean temperatures do not exceed about $-5^{\circ} \mathrm{C}$. The latter extends around the western and southern summit region within a broad area above the $2500 \mathrm{~m}$ contour. A criterion for separating the two is the $-7 \mathrm{~dB}$ isoline of $A$ (Fig. 5) which follows the locus of points along the spine of the ice sheet. This line follows the topographic barrier discussed by Ohmura and Reeh (1991) in their discussion of solid precipitation patterns.

\section{Delineating the dry-snow line}

Benson (1962) delimits the lower extent of the dry-snow zone as corresponding to the $-5^{\circ} \mathrm{C}$ mean summer season isotherm, where it intersects the snow surface. This postulation is made on the basis of diagenesis of grains alone. If summer surface temperatures rise above $-5^{\circ} \mathrm{C}$, the process of equi-temperature metamorphism is accelerated, ensuring grain growth, sintering of grain clusters and often refreezing of meltwater in the snow. Such a gross change in diagenetic processes is reflected in the data since the microwaves are so sensitive to melt, we can map the dry-snow zone simply as the portion of Greenland which shows negligible change in time-series data. It has not previously been possible to map this line using visible wavelength-satellite data (Williams and others, 1991); however, the penetrating capabilities of microwaves enable such a demarcation. Late in September, the cold wave has penetrated downward into the snowpack beyond the old summer surface. After this date there is a relatively strong delineation between the drysnow and the percolation facies downslope, where melt has occurred. The strong gradient between low values of $A$ in dry snow and high $A$ in the percolation zone is used as a locator, and model simulations for Figure 5 values suggest a $40^{\circ}$ incidence back-scatter value of $-5 \mathrm{~dB}$ as a good dry-snow line marker. The result is a map where the line closely follows the $2500 \mathrm{~m}$ contour in south-central Greenland (Fig. 15), falling below $2000 \mathrm{~m}$ at $75^{\circ} \mathrm{N}$ latitude on the west coast.

\section{Percolation zone}

By late September, the contrast between the percolation zone and the dry-snow zone is large enough that mapping the upslope extent of the percolation zone is relatively straightforward. The sequence of maps in Figure 5 also demonstrates that the percolation zone becomes more extensive and marked as the $0^{\circ} \mathrm{C}$ isotherm moves downslope in the fall. In this region of snow, meltwater percolates downward into the snowpack. Often it refreezes at depth in cold snow, or alternatively it may penetrate freely in pipes to the depth of the first stratigraphic impediment. The further downslope, the lower the net annual accumulation, and thus the shallower this impediment becomes. The lower limit of the percolation zone therefore marks the wet-snow facies.

\section{Southern observations}

In the percolation zone, warming is detected in the early parts of the Figure 3 time-series, but $A$ soon assumes a stable level after mid-August (Julian day 228) of $-1.9 \mathrm{~dB}$ at $66^{\circ} \mathrm{N}, 46^{\circ} \mathrm{W}$. Upslope, $\sigma^{\circ}$ decreases, to $A=-5.4 \mathrm{~dB}$ (Fig. 4) at the higher altitude location of $66^{\circ} \mathrm{N}, 44^{\circ} \mathrm{W}$. Annual accumulation increases with altitude, and the seasonal mean temperatures are colder, thus reducing the rate of grain growth. Above the equilibrium-line altitude (ELA) (at around $1200 \mathrm{~m}$ on Jakobshavns Isbræ), balance measurements can be used to infer residual snow depths at the end of the summer melt. Along the EGIG line at $1700 \mathrm{~m}$ altitude, the balance is typically $0.5 \mathrm{~m}$ w.e. year ${ }^{-1}$ (i.e. over $1 \mathrm{~m}$ accumulation of snow at a density of $0.45 \mathrm{Mg} \mathrm{m}^{-3}$ ).

Swift and others (1985) considered the volumescattering mechanisms in simulations of the back-scatter from the percolation zone by using an unbounded halfspace of scatterers. However, it is not necessary to invoke a strong volume-scattering layer to simulate the bright levels of back-scatter observed at Ku-band. Results shown in Jezek and others (1993) suggest that there is some dominant stratigraphic feature which regulates shortwavelength percolation-zone scattering. They show that there is a strong frequency dependency to back-scattering. Longer wavelengths such as L-band (21 cm wavelength) penetrate deeper, possibly penetrating the multiple layers found in this glacial regime (Echelmeyer and others, 1992) to be scattered off the ice glands and lenses found up to a few meters beneath the surface. Contrasting Xband ( $3 \mathrm{~cm}$ wavelength) measurements by Forster and others (1991) indicate that the strongest returns come from annual layers at intervals beneath the surface which are shallower than $3 \mathrm{~m}$. Recent findings from Greenland, using a Ku-band instrument during field experiments in 1991, also indicate that the largest proportion of backscattered returns occurs from an ice layer just beneath the annual snow accumulation (Jezek and Gogineni, 1992). Using a time-gated scatterometer, they demonstrate that the returns $\left(\right.$ at $\theta=45^{\circ}$ ) from a depth range equal to the depth of the first ice layer were much stronger than those from either the surface of the snow or other ranges. Using the simple 2 layer ice/snow model the primary response from the upper layer is formulated in terms of a nonstratified Rayleigh layer upon an ice horizon of finite thickness. This follows work by Mader (1991), which built on a simple scattering model applied by Jezek and 
others (1993). The simulation results support these postulates.

Field measurements by Echelmeyer and others (1992) at altitudes between 1300 and $1600 \mathrm{~m}$ on Jakobshavns Isbræ illustrate the typical conditions during the summer months (albeit during a cold summer season). Their data indicate weakly stratified material (from net seasonal accumulation) lying upon some dominant, spatially contiguous ice layer or relatively dense internal boundary. For example, at $1520 \mathrm{~m}$ Echelmeyer and others, (1992) measured a $5 \mathrm{~cm}$ thick layer of ice at $30 \mathrm{~cm}$ depth, associated with the summer surface. Then at around $70 \mathrm{~cm}$ depth was another $15 \mathrm{~cm}$ thick ice layer this time associated with percolation to the depth of the previous summer surface. The mean density of the firn separating each ice layer was measured typically to be $0.45 \mathrm{Mg} \mathrm{m}^{-3}$. When dry, this snow would have large grains, likely on the order of $1-2 \mathrm{~mm}$ diameter. Echelmeyer and others (1992) also reported that this ice layer is almost continuous at about $0.2-0.4 \mathrm{~m}$ depth in the elevation range from about 1300 to $1600 \mathrm{~m}$. It was often a few centimeters thick and so hard that it prevented stake emplacement without drilling in many places. Moving upslope and inland to the Crawford Point site (C.P. in Figure 1), occupied by Jezek and his co-workers at an altitude of $1900 \mathrm{~m}$, similar stratigraphic features are found. The main real difference in snow-pit characteristics is the considerably higher annual accumulation measured at the Crawford Point site. Ohmura and Reeh (1991) indicate an annual accumulation of over $50 \mathrm{~cm}$ w.e. at this site. If a density of $0.45 \mathrm{Mg} \mathrm{m}^{-3}$ is assumed, as appears typical from Benson's snow pits along this transect, then this snow water equivalent represents over $1 \mathrm{~m}$ of snow accumulation. Indeed, Jezek and Gogineni (1992) reported a value of about $140 \mathrm{~cm}$ of snow in June 1991.

The simulation in Figure 13 shows $\sigma^{\circ}$ versus $\theta$ for the medium specified. Model parameters were set using density and grain-sizes comparable to those values given for the snowpack at Crawford Point, but used to simulate fall conditions at the end of the time-series shown in Figure $3 \mathrm{a}$. The data points overlaid on the simulated curves in Figure 13 are the same as shown in Figure 3b, plots (2) and (3). Notably, the annual accumulation for the region shown in Figure 3 is less than that directly east of Jakobshavns Isbræ. Reducing the snow depth to $0.7 \mathrm{~m}$ increases the strength of the surface returns slightly, because the surface scattering from the ice layer beneath becomes significant. The layer 2 roughness for curve B has a standard deviation of $4.5 \mathrm{~mm}$ and a correlation length of $7.0 \mathrm{~cm}$. The match between Figure $3 \mathrm{~b}$ and simulated scattering from this medium-rough surface is extremely good.

\section{Multi-layered physical models}

It should be noted from the model simulations that the level of $\mathrm{Ku}$-band volume-scattering from the percolationzone snow becomes significant once snow grains reach diameters of around $1 \mathrm{~mm}$. Neither deep-snow nor ice lenses are required to maintain the high incidence-angle values of around $7 \mathrm{~dB}$ seen in Figures 3 and 13. Together with the snow- and ice-layer scattering contributions, snow-grain volume-scatter is sufficient to match levels of

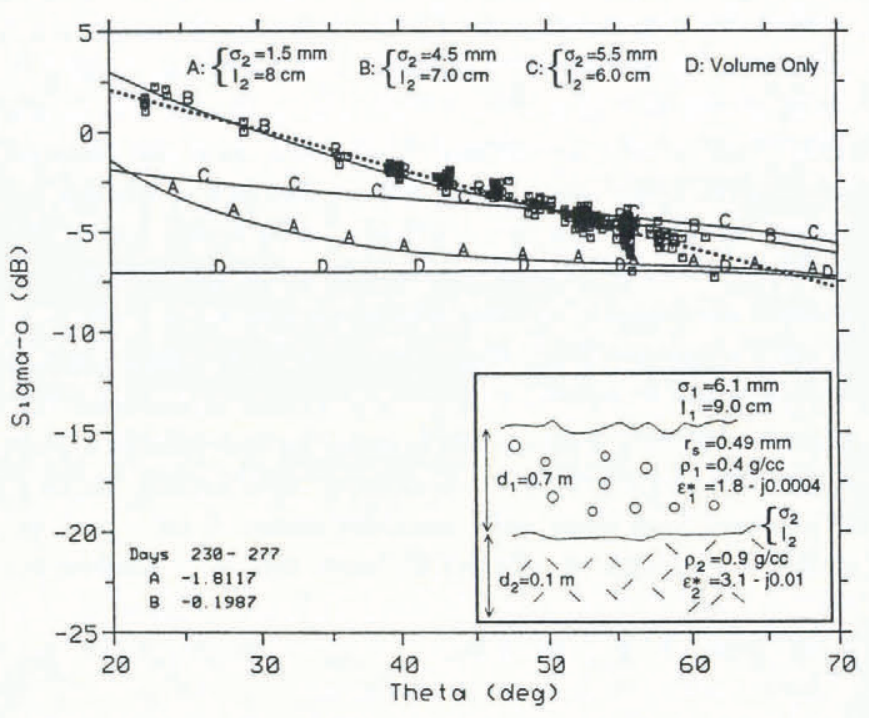

Fig. 13. Plot of $\sigma^{\circ}$ versus $\theta$ for a simulation example corresponding to a simple 2 layer model for the percolation zone. The inset describes the layer properties used as model inputs. Parameter inputs were selected to match surfaceproperties measurements in a region typical of region $b$, Figure 3. Data points from Figure 3b(2) and (3) are overlain.

scattering observed in SASS data. While this is not a comprehensive description of the multiple layers or indeed the sub-surface ice pipes and lenses, it does describe two uppermost layers which effectively impact the higher-frequency microwave scattering. There is no doubt that a more comprehensive physical description of the snow and ice layers becomes necessary in the case of longer-wavelength microwave scattering. Indeed, dipole scattering from decimeter-scale, vertically oriented ice bodies (such as ice pipes) is being investigated as a means of explaining some of the lower-frequency scattering phenomena observed by E. Rignot (personal communication), Jezek and Gogineni (1992) and Jezek and others (1993).

\section{Wet-snow zone}

Moving downslope into the heart of the melt zone, the seasonal $0^{\circ} \mathrm{C}$ isotherm penetrates down to a few meters' depth. At Jakobshavns Isbræ, melt rates up to $0.5 \mathrm{~cm} \mathrm{~d}^{-1}$ are possible and meltwater either is suspended between snow grains or filters down to form superimposed ice on the dense iced firn or summer ice surface beneath. By definition the wet-snow zone encompasses the area where the surface is covered by wet or saturated snow at a temperature of $0^{\circ} \mathrm{C}$. Further downslope, the snow cover is more patchy and the wet snow tends to survive in topographic lows in what Echelmeyer and others (1992) call "slush swamps". The end of continuous snow and the beginnings of areas of discontinuous saturated snow mark the lower boundary of the wet-snow zone, the firn or snow line.

The presence of wetness results in limited penetration of $\mathrm{Ku}$-band signals into the snow and firn. With only a few per cent liquid water by volume, absorption extinguishes the transmitted waves within a few wavelengths. Thus, sub-surface conditions become cam- 
ouflaged and impossible to detect. Notwithstanding this deficiency, dielectric properties of wet snow change dramatically as the surface snow becomes wetted, thereby offering some potential for relating different signatures to different snow wetnesses. As soon as the snow has enough liquid water suspended between the grains (i.e. pendular regime), back-scatter becomes dominated by surface scattering and reflection and thus also the roughness of the snow surface.

Wet snow is relatively smooth in contrast to dry snow or bare ice, according to measurements by Rott and others (1985). Typical roughness values quoted by Shi and Dozier (1992) indicate rms heights ranging from 0.4 to $1.4 \mathrm{~cm}$ (mean of $0.7 \mathrm{~cm}$ ) with correlation lengths from 1.56 to $9.0 \mathrm{~cm}$. For a snowpack with $6 \%$ water (by volume), Rott and others (1985) measured a rms surface height of $0.61 \mathrm{~cm}$ and correlation length of $9.1 \mathrm{~cm}$ (rms slope of $0.24 \mathrm{rad}$ ), which fall within the range quoted by Shi and Dozier (1992). These values are used as scaling parameters in the following model simulations.

\section{Southern wet-snow zone}

A model result is compared in Figure 14 with the SASS data points from region i. Though the data (thick dotted line) closely match the model result (curved solid line), two populations of points are evident, especially between $45^{\circ}$ and $60^{\circ}$. One satisfies a specular surface with a small contribution by volume-scatter (at a level of around $-20 \mathrm{~dB}$ ), while the other more closely traces the thin dashed curve for pure surface scattering (albeit with a higher $B$ value). Wetter regions have saturated surfaces and negligible volume-scatter, with an absence of data points above $-25 \mathrm{~dB}$ at angles over $60^{\circ}$ incidence. Since surface scattering is dominant, the values of the firn/ice interface roughness are unimportant and unnecessary in

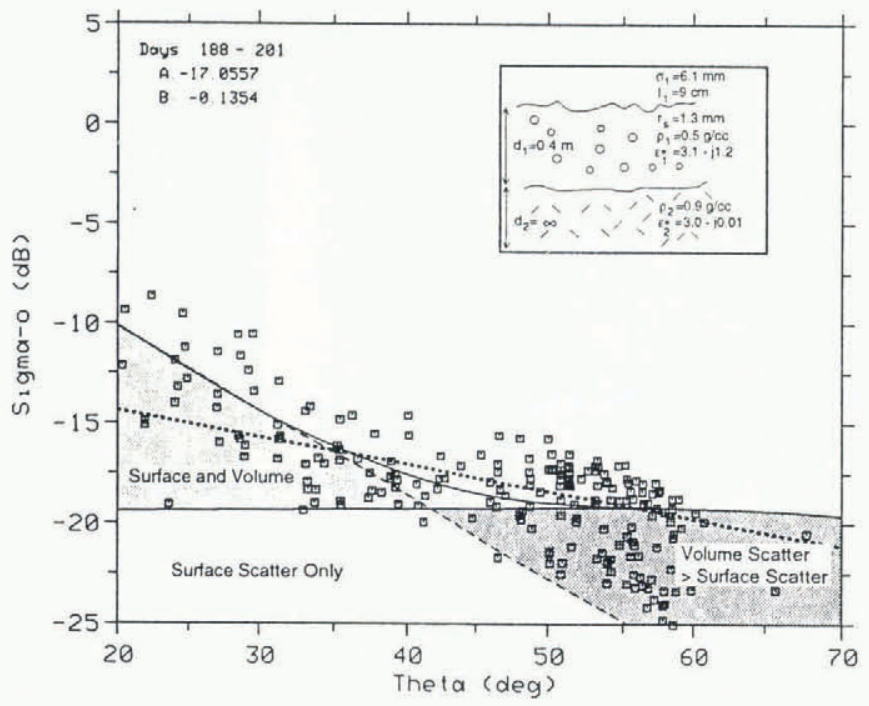

Fig. 14. Plot of $\sigma^{\circ}$ versus $\theta$ for $1^{\circ} \times 2^{\circ}$ study region $i$ in the southern wet-snow zone. Model simulation results are indicated and surface and volume contributions are shaded. The thin dashed line indicates simulated surface scattering only, while the horizontal solid line at $-19 \mathrm{~dB}$ marks the simulated volume-scattering component. The curved solid line signifies the total of surface and volume-scattering sources, and the corresponding SASS data are indicated as a thick dotted line.
Figure 14. Results show region i to have a relatively reflective surface but the resolution of the system limits the purity of the signatures. Comparisons with Figure 5 clearly demonstrate that the lowest back-scatter originates from wet snow and that mapping the wet-snow region is optimal in late June-early July.

To match observed wet-snow back-scatter with model simulations, it is necessary to increase extinction and almost completely switch off dry-snow volume-scattering from snow grains. This is achieved by adding only 2 or $3 \%$ liquid water by volume in firn of densities of around $0.5 \mathrm{Mg} \mathrm{m}^{-3}$ with grain diameters of $1-1.5 \mathrm{~mm}$. This reduces penetration within the isothermal surface snow $\left(\right.$ at $0^{\circ} \mathrm{C}$ ) to the order of a few wavelengths. $\sigma^{\circ}$ at $40^{\circ}$ is then typically less than $A=-12 \mathrm{~dB}$. Thus, the $-12 \mathrm{~dB}$ line may then be used as the delimiter of the upper extent of the wet-snow zone. At lower altitudes the annual accumulation depth of $0.3-0.4 \mathrm{~m}$ often becomes saturated at the end of summer. As snow-free water content climbs, the scattering loss factor increases exponentially and the permittivity climbs steadily. For a grain radius of $0.5 \mathrm{~mm}$, water content of $10 \%$ by volume and density of $0.5 \mathrm{Mg} \mathrm{m}^{-3}$ (Fig. 14), the permittivity exceeds that of ice (i.e. $>3.0$ ), while the dielectric loss attains values near 1.0. The Figure 14 simulation, with saturated firn above hard ice, shows that the volume-scattering is lowered to $-20 \mathrm{~dB}$ or less. In this surface-scattering-dominated regime, the rms roughness and correlation function are important to $B$. However, increasing wetness drives up the complex dielectric constant and the reflectivity, which, even with the roughness values specified, causes decreased back-scatter at $40^{\circ}$ (i.e. reduced $A$ ). More extreme examples in Shi and Dozier (1992) demonstrate that if the surface is much rougher, then increased wetness could cause an increase in high-incidence back-scatter.

It should be noted that the saturation line is not evident in the mid-summer microwave data, as there is no way of sensing if the snow is saturated to the base of the annual-accumulation layer. This would require determining the snow-wetness values based upon the dielectric properties of the surface. Recent work by Shi and Dozier (personal communication) suggests that this may become possible in multi-frequency aircraft SAR data.

Wet-snow data values extracted from region $\mathrm{j}$ in Figure 1 show similar characteristics to SASS data points in Figure 14, confirming that the wet-snow zone has the most variable microwave signatures and thus has the most spatially variable physical properties.

\section{Fall cooling in the wet-snow zone}

Evidence supporting the hypothesis that large snow grains are the primary mechanism for dry-snow volumescattering is found towards the end of the wet-snow timeseries in Figure 2a. As the $0^{\circ} \mathrm{C}$ isotherm descends downslope and the wet-snow zone refreezes, $A$ soon climbs to higher values with extremely low variability. The level of volume-scattering after Julian day 240 in Figure $2 \mathrm{~b}$ cannot be caused by large ice lenses or glands, because originally the whole active surface layer was wet or saturated. Refreezing does not suddenly enable ice-lens growth: instead, grains of snow bond together and grow significantly in size as irregular clusters during the summer months. Firnification processes thus cause a 
high level of back-scatter similar to what occurs in the percolation-zone examples from region $b$ by the end of the time-series (cf. Figs $2 b(3)$ and $3 b(3)$ ).

\section{Ice and ablation facies}

The ablation zone is at altitudes typically less than $1200 \mathrm{~m}$, as indicated by Echelmeyer and others (1992) for the area of Jakobshavns Isbræ. Mid-summer rates of ablation can be as high as $4.4 \mathrm{~cm} \mathrm{~d}^{-1}$. Thus, the summer surface comprises predominantly bare ice with a typical density of around $0.9 \mathrm{Mg} \mathrm{m}^{-3}$. Surface melting in this zone results in runoff in supraglacial streams.

The SAS-image pixel values indicate that some of the pixels include a mixture of surfaces. Bare ice surfaces (from which the snow cover has been melted away) may be wet from rain and melting and may have a high dielectric constant at the surface. Surface scatter dominates and the roughness predetermines the level of the back-scatter curves. Measurements of bare glacial ice by Rott and others (1985) indicate such surfaces to be relatively rough. Differential melting causes features such as cryoconite holes, and such a bare ice surface was observed to have a rms surface height of $1.74 \mathrm{~cm}$ and correlation length of $8.4 \mathrm{~cm}$ (Rott and others, 1985).

Model simulations of fairly smooth wet-ice surfaces result in back-scatter signatures with a gradient much steeper than the data because SASS cells incorporate a mixture of surface types. Data plots from region i (Fig. 1) indicate two predominant families of curves. One has a steep group of points aligned with a gradient $B$ of $0.3-$ $0.4 \mathrm{~dB} \mathrm{deg}^{-1}$. This is typical of smooth ice. A value of $A$ inferred from a regression fit to this family of points would be lower than is currently observed, i.e. $A$ values would cluster around $-20 \mathrm{~dB}$. A result of the fitting process in a large cloud of mixed back-scatter points of different families appears to be an artificially low gradient $B$ and therefore a higher value of $A$. In order to push up simulated $\sigma^{\circ}$ to the same levels (and to reduce $B$ ) the roughness must be increased to an unrealistic and unlikely level, and simulated results are therefore not shown.

\section{Separating the ablation and wet-snow zones}

Due to a lack of contrast between the ablation zone and the wet-snow zone, it is difficult to make a distinction based upon $\sigma^{\circ}$ values from our time-series data. Without a longer seasonal-change cycle, and without more overlapping higher-resolution SAR data, it is currently impossible to extract the effects of mixed pixels. A small exercise was conducted on the relationship between the observed variability and individual cell signatures. It was necessary to check whether the variations in the $A$ and $B$ plots were a result of spatial or temporal changes in surface properties within any given sample box. It was found that it is largely differences in the rates of change of surface dielectric conditions within each cell that cause scatter in the time-series estimates of $A$ and $B$.

When mixed bare-ice and slushy-snow patches are present, surface wetting causes some differences in the responses of the bare ice and wet snow. Depending upon the shape and size of the imaging cell, at any given pass of the SASS, this results in a mixture of signatures over time. The only way to extract the location of the upper

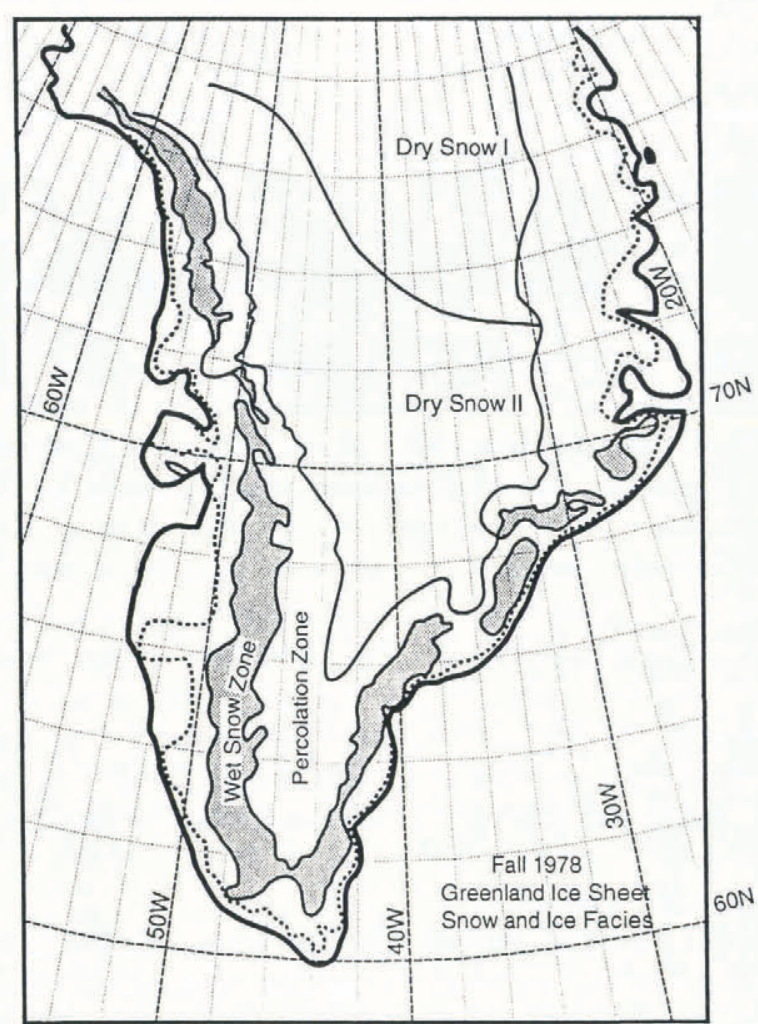

Fig. 15. Map showing the postulated locations of key facies and zones extracted from the high-resolution SASS maps.

boundary of the ice or ablation facies is to mark the snow line during mid-summer. Then, the ice and ablation area is simply the remainder of the ice sheet between this line and the outer extent of the ice-sheet, shown in Figure 15 as a dotted line. It is recognized that some unknown error occurs due to the lack of accounting for the superimposed ice zone. Ice-sheet extent and the lower limit of the wetsnow zone (i.e. the "snow" line) are best mapped with the high resolution offered by the SAR on board ERS-1. Even then, there is no convenient way of discriminating the ablation area or area of net melting from the remainder of the ice facies, since no recognizable physical differences exist between superimposed ice (above the equilibrium-line altitude) and ablation-zone bare ice.

\section{DISGUSSION AND CONGLUSIONS}

Evidently, time-series data are effective for monitoring developments in the scattering signatures through the summer-fall transition. Seasonal changes result in recognizable trends in SASS enhanced-resolution images of Greenland. Since seasonal transitions are also responsible for the physical evolution of surface properties, there is a strong basis for the identification of the primary delimiters between snow facies. Boundaries mark important transitions between melting or freezing processes, and thus net accumulation and ablation. In glacier massbalance terms it is important to monitor the extent of the dry- and wet-snow zones to observe variations in this balance.

The sensitivity of these SASS data to the location of the boundaries between wet and dry surfaces, and 
similarly between strong and weak volume-scatterers, indicates that it is possible to delineate a number of important snow facies. We have clearly demonstrated that the dry-snow line can be mapped at the end of the summer-fall transition (late September). It bounds the area of dry snow, characterized by negligible change throughout the microwave time-series, and marks the upper extent of the percolation zone. In contrast, the wetsnow line appears most clearly at the end of summer (early July), demarcating the lowest back-scatter wet snow zone and the relatively bright percolation zone upslope. The snow line marks the lower boundary of the wet snow and is also mapped in mid-July as the downslope margin of the lowest back-scatter region in Figure 5. At the end of summer, in any normal balance year, the snow or firn line should closely approximate the location of the ELA.

These SASS image time-series show that it is possible to identify the lower limit of the wet snow (snow line), at the end of summer when the back-scatter within this zone reaches a minimum. The snow line, however, is often not contiguous, owing to the patchy nature of the residual summer snow cover reflected as mixed SASS pixels. Since recognition of the snow line is important to monitoring the overall balance situation of the ice-sheet it is recommended that complementary, higher-resolution SAR images be used if a more precise location of the lower boundary of the wet-snow zone is required. Nevertheless, Figure 5, together with the model simulations, indicates that these dry, wet, and snow or firn lines can clearly be mapped at certain times throughout the year. Though the dry- or wet-snow lines may not be as important to monitor in balance terms, they mark the upper limit of seasonal melting at the surface of the snowpack and the extent of summer, saturated snowpack. Climatically, they are sensitive indicators of changes in the pattern of melting on the ice-sheet, and thus of the overall pattern of net accumulation.

Using the rationale described above, in Figure 15 we have generated a map from the SASS image time-series which shows the locations of these facies for 1978. It is based upon the scattering signatures and their relationship with the surface properties, together with the supporting information provided by physical and scattering models. Postulated locations of the facies boundaries can be compared with similar maps generated by future scatterometers to monitor the inter-annual variations of the boundary locations.

Major features in Figure 15 include the fact that the "apparent" dry-snow zone is different in extent and shape from Benson (1962). This refinement in mapping technique, together with the greater objectivity and precision, is expected to give a more accurate spatial interpretation of dry-snow surface conditions (with all due credit and acknowledgement to Benson's pioneering work). The fact that negligible change occurs in the proposed new dry-snow zone supports the argument for a revised dry-snow zone. Importantly, the southwestern margin of the dry-snow zone is at a significantly lower altitude than that originally mapped. Since the summer of 1978 was not especially cooler than normal, it would appear that the general 30 year cooling trend suggested by Chapman and Walsh (1993) had indeed already been manifested in the level of the dry-snow line location. If, as Chapman and Walsh (1993) suggest, a cooling of up to $-0.6 \mathrm{deg}$ per decade has taken place between 1960 and 1990 , then over the 23 years between the measurements of Benson (1962) and Seasat, significant change could have occurred. It remains to be demonstrated as to whether other satellite results paint a similar picture. Early findings by Jezek and Gogineni (1992) appear to show a striking similarity in the position of the dry-snow line when SASS and ERS-1 SAR data are compared. Their study, however, was limited to a transect from western Greenland towards the northeast of the ice sheet, whereas our results indicate the most significant differences in the dry-snow line to the south and southwest of the summit.

While SASS data is over a decade old, it provides a unique historical data set to study climate change. By using the enhanced-resolution scatterometer imaging technique of Long and others (1993), we have been able to generate $\mathrm{Ku}$-band images of $A$ and $B$. Although these images have only medium-scale resolution $(6 \mathrm{~km})$, they provide an ice-sheet-wide view of the ice conditions over Greenland during the summer and early fall of 1978. A time-series of these images clearly delineates the summer melt region and its movement in altitude with time and seasonal air temperature. Using simplified scattering models we have been able to delineate the wet, percolation and dry-snow zones from the images. These and C-band results from AIRSAR (J. van Zyl, personal communication), together with recent ERS-1 results (Jezek, 1993), show that the main buried surface scatterer at the stratigraphic discontinuity between annual accumulation units (in the percolation and drysnow zone) is switched on and off as the melt/freeze cycle takes place. Wet snow is demonstrated to camouflage subsurface conditions, due to increased surface reflection and absorption within the surface layers.

We conclude that scatterometers can be used effectively to study glacial ice in Greenland, particularly when coupled with the SIRF algorithm. We note that the imaging technique can also be applied to the ERS-1 scatterometer and that assumptions in section 4 may be relaxed when applying the method to suitably modified future scatterometers, since multiple orbit passes may not be required (Long and others, 1993). This approach will also be used with data from future missions such as the Ku-band NSCAT (Naderi and others, 1991) to study the inter-annual variability of the positions and areal extent of these zones. Since the location of the facies boundaries will change with changes in climate, the fundamental differences between the current situation (from ERS-1 data) and Seasat SASS data (from 1978) should be investigated next. Furthermore, with low-cost modifications to future planned scatterometers such as the NASA EoS-era scatterometer, the imaging resolution can be further improved to as low as $1-2 \mathrm{~km}$ (Long and others, 1993). This, coupled with very frequent, multipleincidence angle observations, will significantly enhance the application of future scatterometer data for the study of polar ice. In particular, multiple-incidence angle measurements are better for use in inferring ice condition/age and snow cover. For this reason alone they provide a unique source of back-scattering information, currently unobtainable from higher spatial-resolution 
imaging radar-remote-sensing techniques such as synthetic aperture radar.

\section{ACKNOWLEDGEMENTS}

We wish to acknowledge the support of the National Aeronautics and Space Administration (NASA) programs in Physical Oceanography (D. Adamec) and Polar Sciences (R. Thomas). In addition, we thank D. Early and R. Shaw for their assistance in processing the data, and R. Braithwaite for his valuable review and critique of our manuscript. SASS GDR data were obtained from the PoDAAC at the Jet Propulsion Laboratory. M.R.D conducted this work at the Jet Propulsion Laboratory, California Institute of Technology, under contract to NASA.

\section{REFERENGES}

Benson, C.S. 1962. Stratigraphic studies in the snow and firn of the Greenland ice sheet. SIPRE Res. Rep. 70.

Benson, C. S. 1967. Polar regions snow cover. In Ôura, H., ed. Physics of snow and ice. International Conference on Low Temperature Science, August 14-19, 1966, Sapporo, Japan. Proceedings. Vol. 1, Part 2. Sapporo, Hokkaido University. Institute of Low Temperature Science, 1039-1063.

Bindschadler, R. A., K. C. Jezek and J. Crawford. 1987. Glaciological investigations using the synthetic aperture radar imaging system. Ann. Glaciol., 9, 11-19.

Bracalente, E. M., D. H. Boggs, W. L. Grantham and J. L. Sweet. 1980. The SASS1 scattering coefficient $\sigma^{\circ}$ algorithm. IEEE 7. Oceanic Eng., OE-5, 145-154.

Braithwaite, R.J., O.B. Olesen and H.H. Thomsen. 1992. Calculated variations of annual ice ablation at the margin of the Greenland ice sheet, West Greenland, 1961-90. F. Glaciol., 38(129), 266-272.

Chapman, W.L. and J.E. Walsh. 1993. Recent variations of sea ice and air temperature in high latitudes. Bull. Am. Meteorol. Soc., 74(1), 33-47.

Drinkwater, M. R. 1988. Radar altimetric studies of polar ice. (Ph.D. thesis, Cambridge University.)

Drinkwater, M. R. 1989. LIMEX '87 ice surface characteristics: implications for C-band SAR backscatter signatures. IEEE Trans. Geosci. Remote Sensing, 27(5), 501-513.

Echelmeyer, K., W.D. Harrison, T. S. Clarke and C. Benson. 1992. Suríicial glaciology of Jakobshavns Isbræ, West Greenland: Part II. Ablation, accumulation and temperature. F. Glaciol., 38(128), 169-181.

Forster, R. R., C. H. Davis, T.W. Rand and R. K. Moore. 1991. Snowstratification investigation on an Antarctic ice stream with an X-band radar system. F. Glaciol., 37(127), 323-325.

Jezek, K. C. 1993. Spatial patterns in backscatter strength across the Greenland ice sheet. Symposium report from Cannes ERS-1 investigators meeting. Paris, European Space Agency, 68-69. (Special Publication 359.)

Jezek, K. C. and S. Gogieni. 1992. Microwave remote sensing of the Greenland ice sheet. IEEE Geosci. Remote Sensing Society Newsletter, 85, 6-10.

Jezek, K. C., J.P. Crawford, R. Bindschadler, M. R. Drinkwater and
R. Kwok. 1990. Synthetic aperture radar observations of the Greenland ice sheet. Proceedings of the Second Airborne Synthetic Aperture Radar (AIRSAR) Workshop, fune 7 and 8, 1990. JPL Publ. 90-56, 2128.

Jezek, K. C., M.R. Drinkwater, J.P. Crawford, R. Bindschadler and R. Kwok. 1993. Analysis of synthetic aperture radar data collected over the southwestern Greenland ice sheet. 7. Glaciol., 39(131), 119-132.

Jones, W.L. and 7 others. 1982. The Seasat-A satellite scatterometer: the geophysical evaluation of remotely sensed wind vectors over the ocean. F. Geophys. Res., 87(C5), 3297-3317.

Livingstone, C.E. and M. R. Drinkwater. 1991. Springtime G-band SAR backscatter signatures of Labrador Sea marginal ice: measurements versus modeling predictions. IEEE Trans. Geosci. Remote Sensing, 29(1), 29-41.

Long, D. G., P.J. Hardin and P.T. Whiting. 1993. Resolution enhancement of spaceborne scatterometer data. IEEE Trans. Geosci. Remote Sensing, 31(3), 700-715.

Mader, R. E. 1991. Synthetic aperture radar imaging of glacial ice. Lawrence, KS, University of Kansas. Remote Sensing Laboratory. (RSL Technical Report 8291-1.)

Naderi, F., H. Freilich and D.G. Long. 1991. Spaceborne radar measurement of wind velocity over the ocean - an overview of the NSCAT scatterometer system. Proc. IEEE, 79(6), 850-866.

Ohmura, A. and N. Reeh. 1991. New precipitation and accumulation maps for Greenland. F. Glaciol., 37(125), 140-148.

Partington, K. C., J. K. Ridley, C. G. Rapley and H.J. Zwally. 1989. Observations of the surface properties of the ice sheets by satellite radar altimetry. F. Glaciol., 35(120), 267-275.

Pfeffer, W. T., T.H. Illangasekare and M. F. Meier. 1990. Analysis and modeling of melt-water refreezing in dry snow. F. Glaciol., 36(123), 238-246.

Rott, H., G. Domik, C. Mätzler, H. Miller and K. G. Lenhart. 1985. Study on the use and characteristics of SAR for land snow and ice applications. Final report. Paris, European Space Agency. (ESA Report 5441/83/D/ IM/SC.)

Shi, J.-C. and J. Dozier. 1992. Radar backscattering response to wet snow. In Williamson, R., ed. 1992. IGARSS'92. International Geoscience and Remote Sensing Symposium. International Space Year: space remote sensing ... Houston, Texas, May 26-29, 1992. Vol. 2. New York, Institute of Electrical and Electronics Engineers, 927-929.

Swift, C. T., P. S. Hayes, J. S. Herd, W. L. Jones and V. E. Delnore. 1985. Airborne microwave measurements of the southern Greenland ice sheet. F. Geophys. Res., 90(B2), 1983-1994.

Thomas, R. H. and 8 others. 1985. Satellite remote sensing for ice sheet research. Washington, DC, National Aeronautics and Space Administration. (NASA Technical Mememorandum 86233.)

Tiuri, M.E., A. H. Sihvola, E. G. Nyfors and M. T. Hallikainen. 1984. The complex dielectric constant of snow at microwave frequencies. IEEE 7. Oceanic Eng., OE-9(5), 377-382.

Ulander, L. M. 1985. Airborne radar altimetry over the Greenland ice sheet. (M.Sc. thesis, University of London.)

Williams, R. S., Jr, D. K. Hall and C. S. Benson. 1991. Analysis of glacier facies using satellite techniques. F. Glaciol., 37(125), 120-128.

Winebrenner, D. P. and 15 others. 1992. Microwave sea ice signature modeling. In Carsey, F.D., ed. Microwave remote sensing of sea ice. Washington, DC, American Geophysical Union, 137-175. (Geophysical Monograph 68.)

Zwally, H.J., A.C. Brenner, J.A. Major, R.A. Bindschadler and J. G. Marsh. 1989. Growth of Greenland ice sheet: measurement. Science, 246(4937), 1587-1591.

The accuracy of references in the text and in this list is the responsibility of the authors, to whom queries should be addressed. 